\title{
molecules
}

ISSN 1420-3049

www.mdpi.com/journal/molecules

Article

\section{Bio-Activity and Dereplication-Based Discovery of Ophiobolins and Other Fungal Secondary Metabolites Targeting Leukemia Cells}

Tanja Thorskov Bladt ${ }^{1, \dagger}$, Claudia Dürr ${ }^{2, \dagger}$, Peter Boldsen Knudsen ${ }^{1}$, Sara Kildgaard ${ }^{1}$, Jens Christian Frisvad ${ }^{1}$, Charlotte Held Gotfredsen ${ }^{3}$, Martina Seiffert ${ }^{2}{ }^{*}$ and Thomas Ostenfeld Larsen ${ }^{1, *}$

1 Department of Systems Biology, Technical University of Denmark, Søltofts Plads, Building 221, Kgs. Lyngby DK-2800, Denmark; E-Mails: ttb@bio.dtu.dk (T.T.B.); pebok@bio.dtu.dk (P.B.K.); sarki@bio.dtu.dk (S.K.); jcf@bio.dtu.dk (J.C.F.)

2 German Cancer Research Center, Molecular Genetics, Im Neuenheimer Feld 280, Heidelberg D-69120, Germany; E-Mail: C.Duerr@dkfz-heidelberg.de

3 Department of Chemistry, Technical University of Denmark, Kemitorvet, Building 201, Kgs. Lyngby DK-2800, Denmark; E-Mail: chg@kemi.dtu.dk

$\dagger$ These authors contributed equally to this work.

* Authors to whom correspondence should be addressed;

E-Mails: M.Seiffert@dkfz-heidelberg.de (M.S.); tol@bio.dtu.dk (T.O.L.);

Tel.: +49-6221-42-4586 (M.S.); Fax: +49-6221-42-2995 (M.S.);

Tel.: +45-4525-2632 (T.O.L.); Fax: +45-4588-4148 (T.O.L.).

Received: 12 October 2013; in revised form: 15 November 2013 / Accepted: 21 November 2013 / Published: 26 November 2013

\begin{abstract}
The purpose of this study was to identify and characterize fungal natural products (NPs) with in vitro bioactivity towards leukemia cells. We based our screening on a combined analytical and bio-guided approach of LC-DAD-HRMS dereplication, explorative solid-phase extraction (E-SPE), and a co-culture platform of CLL and stromal cells. A total of 289 fungal extracts were screened and we tracked the activity to single compounds in seven of the most active extracts. The novel ophiobolin $\mathrm{U}$ was isolated together with the known ophiobolins $\mathrm{C}, \mathrm{H}, \mathrm{K}$ as well as 6-epiophiobolins $\mathrm{G}, \mathrm{K}$ and $\mathrm{N}$ from three fungal strains in the Aspergillus section Usti. Ophiobolins A, B, C and $\mathrm{K}$ displayed bioactivity towards leukemia cells with induction of apoptosis at nanomolar concentrations. The remaining ophiobolins were mainly inactive or only slightly active at micromolar
\end{abstract}


concentrations. Dereplication of those ophiobolin derivatives possessing different activity in combination with structural analysis allowed a correlation of the chemical structure and conformation with the extent of bioactivity, identifying the hydroxy group at $\mathrm{C} 3$ and an aldehyde at $\mathrm{C} 21$, as well as the $\mathrm{A} / \mathrm{B}$-cis ring structure, as indispensible for the strong activity of the ophiobolins. The known compounds penicillic acid, viridicatumtoxin, calbistrin A, brefeldin A, emestrin A, and neosolaniol monoacetate were identified from the extracts and also found generally cytotoxic.

Keywords: natural products; ophiobolin U; dereplication; explorative solid phase extraction (E-SPE); filamentous fungi; cytotoxic; cancer; leukemia

\section{Introduction}

Screening and discovery of compounds that act against chronic lymphocytic leukemia (CLL) cells are crucial since CLL is considered as an incurable disease and currently applied treatment strategies primarily aim at prolonging patient survival [1,2]. Filamentous fungi have proven to be an incredible source of diverse bioactive compounds. The continuous improvements of analytical instruments and new approaches for fast dereplication have resulted in an increased interest in natural products discovery [3-5]. CLL is the most common type of leukemia among adults in the Western World. Even though most patients initially show a good response to therapy, relapse of disease is very frequent, with a subsequent increase in chemoresistance [6]. Consequently, there is a great need for discovery and development of new agents. Treatment strategies used today are based on small-molecule alkylating agents such as chlorambucil and fludarabine. These agents are often used in combination with monoclonal antibodies, or more recently inhibitors that target essential signaling pathways in CLL $[7,8]$. In contrast to other cancer cells, the majority of CLL cells is non-proliferating, arrested in $\mathrm{G}_{0} / \mathrm{G}_{1}$ phase of the cell cycle and accumulates in the patients due to apoptosis resistance [1]. In vivo, CLL cells are associated with a survival-inducing microenvironment of stromal cells, non-malignant leukocytes, so-called nurse-like cells, as well as growth and differentiation factors $[9,10]$. Removed from their natural microenvironment, the CLL cells rapidly undergo apoptosis in vitro, even though they are long-living cells in vivo [11]. However, viability of CLL cells can be maintained in vitro by co-cultivation with stromal cells, for example the bone marrow-derived cell line HS-5 [12,13]. Such co-cultures mimic the microenvironment of CLL cells in vivo, they are ideally suited for screening of natural products (NPs) [14]. We have already demonstrated that fungal NPs are a proper source for discovering compounds with activity towards CLL cells in vitro. This was done by identification of chaetoglobosin A from P. aquamarinum. Chaetoglobosin A induced apoptosis in CLL cells more selectively compared to healthy cells with a median lethal dose $\left(\mathrm{LC}_{50}\right)$ of $2.8 \mu \mathrm{M}$ [15].

Novel secondary metabolites produced by filamentous fungi such as Penicillium and Aspergillus are being discovered continuously $[4,16]$. With the increase in target-based specific biological assays, previously described compounds might display novel bioactivities $[17,18]$, justifying their presence in novel screening efforts. Testing all known as well as novel NPs against all disease targets is an impracticable approach, why setting up a suitable strategy is essential to any screening program [19]. 
Targeted screening strategies in NPs-based drug discovery rely on identifying compounds targeting a specific disease or biological mechanism. In such screening campaigns, the selection of fungi is essential and needs to represent as wide a biodiversity as possible, with the hope of an equally high chemodiversity [19]. One strategy to increase chemodiversity for rapid bio-testing is to select strains representing a wide variety of species with a limited number of strains from each species [19,20]. The spectrum of compounds produced by the individual strains can further be diversified or maximized by the 'one strain-many compounds' (OSMAC) approach, through variation of culture conditions [16].

Dereplication is the tentative identification of known NPs in complex mixtures, before unnecessary time is spent on isolating already known compounds. One dereplication approach is based on liquid chromatography-diode array detection-high resolution mass spectrometry (LC-DAD-HRMS) and database searching, which ensures a high throughput and reproducibility [3]. Subsequent to dereplication a separation strategy for preparative isolation of NPs is necessary. Here a small scale preliminary chemical characterization focusing on identification of functional groups is helpful. Co-eluting interferences often experienced in traditional reverse phase (RP) chromatography can be reduced or even completely removed by choosing orthogonal purifications strategies [21]. One approach for prefractionation is explorative solid-phase-extraction (E-SPE) [21] that relies on ion-exchanger columns such as strong anion-exchanger (SAX), mixed mode anion-exchanger (MAX), and strong cation-exchanger (SCX). This method has proven to be very powerful for separating fungal NPs due to the relative high percentages of ionizable functional groups [21].

In this current paper we describe our screening efforts of discovering fungal NPs with bio-activity in a co-culture platform of chronic lymphocytic leukemia (CLL) cells and stromal cells and their retesting in CLL cells cultures in conditioned media of stromal cells [12]. The fungal NPs were tentatively identified by LC-DAD-HRMS based dereplication and extracts were fractionated in order to assign the activity to single compounds [3]. Confidence in this identification was improved by using an E-SPE strategy based on an array of orthogonal separation techniques [19,21]. Thereby among others, ophiobolins were identified and further structural studies were performed by dereplicating different ophiobolin dervatives leading to the identification of chemical moieties and conformations that are indispensable for strong bioactivity. Ophiobolins lacking these moieties possessed either low or no bioactivity.

\section{Results and Discussion}

A total of 289 fungal extracts were prepared from cultivation of 137 fungal strains (Figure 1 and Table S1) on a selection of solid media at variable temperatures in accordance with the OSMAC approach [16]. The extracts were prepared by the micro-extraction method developed by Smedsgaard [22]. To obtain a representative sample of the fungal colonies the plugs were taken across the colony. Sixty one (61) extracts showed activity towards CLL cells (Table S2). Seven of the candidates that displayed the highest level of activity (Figure 1) were selected for further bio-testing. Large-scale extracts were prepared from incubation on the media supporting the highest level of bioactivity, and the extracts were prefractionated before further testing. 
Figure 1. Screening set-up. Two hundred and eighty nine (289) fungal extracts (from 137 fungal strains) were tested for cell death-inducing activity for CLL cells but not for stromal cells. From the 61 active extracts the seven candidates that displayed the highest bio-assay activity were selected for single compound isolation in a large scale and further bio testing.

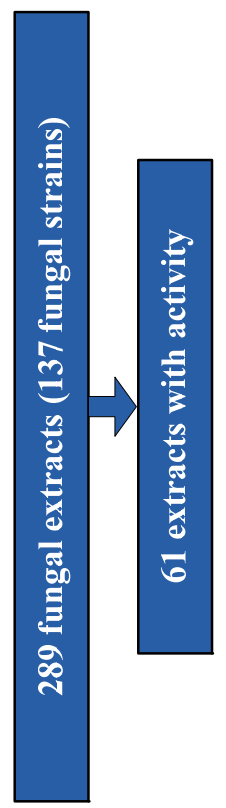

\begin{tabular}{|ll|}
\hline Fungi & Active compound \\
\hline P. pulvillorum & Penicillic acid \\
$P$. brasilianum & Viridicatumtoxin \\
$P$. decumbens & Calbistrin A \\
$P$. cluniae & Brefeldin A \\
Aspergillus sp. (Emericella-like state) & Emestrin A \\
F. compactum & Neosolaniol monoacetate \\
New sp. in Aspergillus section Usti & Ophiobolin K \\
\hline
\end{tabular}

\subsection{MS Based Dereplication of Penicillium pulvillorum Extract}

The extract of $P$. pulvillorum (IBT 22393) was among the candidates that displayed the highest level of activity $(\approx 1.25 \mu \mathrm{g} / \mathrm{mL})$. The first five flash fractions (ranging from $15 \%-40 \%$ organic) were tested active against CLL cells in vitro. LC-DAD-HRMS revealed one major component shared between these fractions, with an elementary composition of $\mathrm{C}_{8} \mathrm{H}_{10} \mathrm{O}_{4}(-0.7$ ppm mass accuracy) (Figure 2). AntiBase2012 [23] revealed penicillic acid as a likely candidate responsible for the observed activity. The tentative identification of penicillic acid was confirmed by comparison of the retention time to a standard from our in-house metabolite database (1,559 standards) as well as comparison of ${ }^{1} \mathrm{H}-$ and ${ }^{13} \mathrm{C}-\mathrm{NMR}$ chemical shifts to the literature data [24].

Figure 2. Dereplication of penicillic acid from $P$. pulvillorum mass spectrum of penicillic acid [23]. The mass spectrum shows a widespread adduct pattern that besides $[\mathrm{M}+\mathrm{H}]^{+}$ contains ions that corresponds to neutral loss of water $\left[\mathrm{M}+\mathrm{H}-\mathrm{H}_{2} \mathrm{O}\right]^{+}$and the sodiated adduct $[\mathrm{M}+\mathrm{Na}]^{+}$, as well as the corresponding dimeric ions $[2 \mathrm{M}+\mathrm{H}]^{+},\left[2 \mathrm{M}+\mathrm{H}-\mathrm{H}_{2} \mathrm{O}\right]^{+}$, and $[2 \mathrm{M}+\mathrm{Na}]^{+}$.

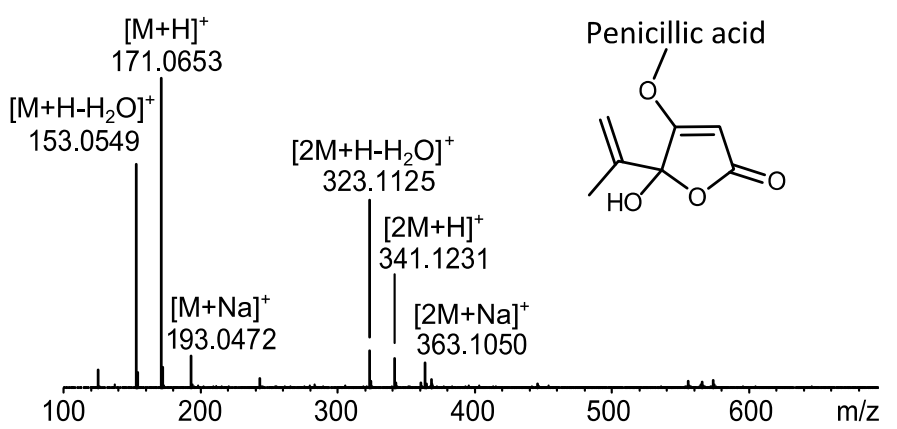


To verify the observed anti-leukemic activity in the extract, penicillic acid was purified and tested on CLL cells, resulting in induced cell death in both CLL and stromal (HS-5) cells. No further work on this extract was done as penicillic acid is regarded as a generally cytotoxic compound [24].

\subsection{Comparative Dereplication Based on Explorative Solid Phase Extraction (E-SPE)}

The E-SPE strategy was applied to a series of highly complex extracts, i.e., P. brasilianum (IBT 22244), P. decumbens (IBT 11843), P. cluniae (IBT 21051), Aspergillus sp. (Emericella-like state) (IBT 22838), and Fusarium compactum (IBT 9034). The extract of P. brasilianum (IBT 22244) was very potent against CLL cells in vitro $(\approx 5 \mathrm{ng} / \mathrm{mL})$ with the active compound retained on both anionexchangers (SAX and MAX) as well as the two normal-phase columns (diol and amino), while unretained on the cation-exchanger (SCX). The combined biological and chromatographic information lead to the conclusion that the bioactive compound contained a strong anion. The large scale extract was fractionated on a SAX column. Comparison of chromatographic peaks from the fraction that contained neutral/basic compounds (Figure 3a) and the fraction with acidic compounds (Figure 3b), showed that the anion-exchange was extremely selective, removing the majority of inactive compounds from the extract.

Figure 3. E-SPE strategy based on a SAX column to separate co-eluting compounds in the crude extract of $P$. brasilianum. (a) UHPLC chromatograms of the SAX fraction that contained neutral/basic compounds. The ion trace of compound I $(\mathrm{m} / \mathrm{z} 462.2387)$ is marked with red; (b) UHPLC chromatogram of the SAX fraction that contained acidic compounds. The ion trace of compound IV ( $\mathrm{m} / z$ 548.1916) is marked with blue; (c) In the crude extract compound I and IV were co-eluting on a RP $\mathrm{C}_{18}$ column.
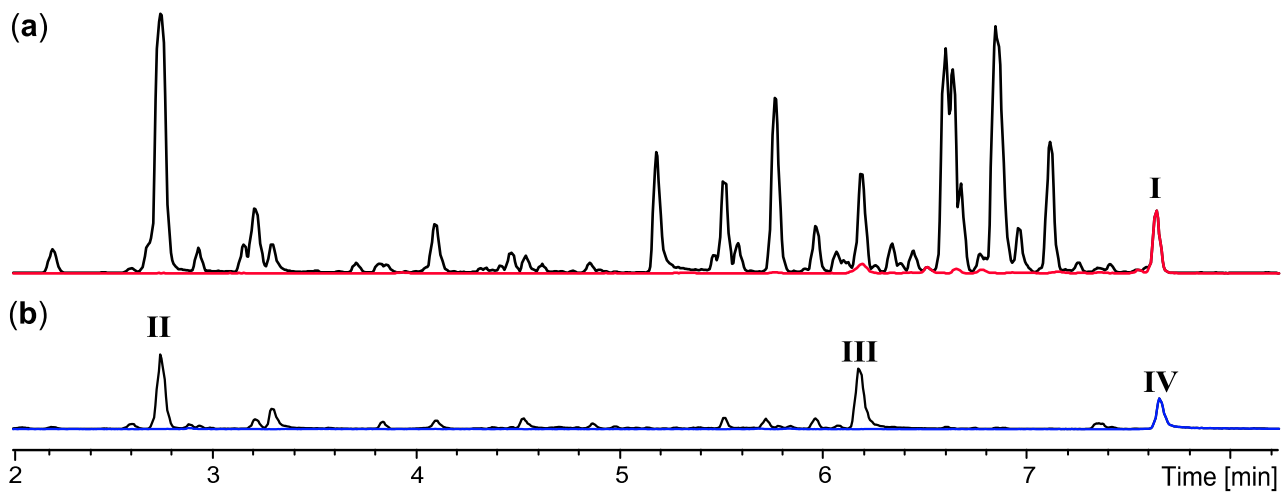

(c)

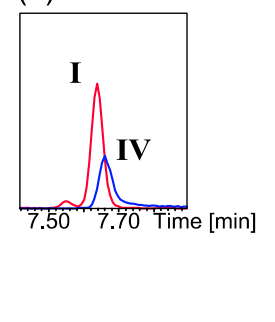

In the initial extract, the two compounds I and IV co-eluted on a $\mathrm{C}_{18} \mathrm{RP}$ column (Figure $3 \mathrm{c}$ ). These were easily and quantitatively separated on the SAX column due to the difference in charged functionalities. Only three major acidic compounds were left in the bioactive fraction (Figures $3 b$ and $4 a$ ), significantly simplifying the subsequent dereplication and purification process. Based on comparative HRMS analysis, compound II was immediately eliminated due to its presence in the inactive neutral/basic fraction. The molecular formula of compounds III and IV were established as $\mathrm{C}_{15} \mathrm{H}_{10} \mathrm{O}_{9}$ $(-0.7 \mathrm{ppm})$ and $\mathrm{C}_{30} \mathrm{H}_{31} \mathrm{NO}_{10}(-0.2 \mathrm{ppm})$, respectively. These were used as queries in AntiBase2012 (Figure 4b) [23]. Compound II had no hits in AntiBase2012 that contained a strong anion, thus likely being a novel compound or novel analogue of a known compound. Compound IV had two hits in 
AntiBase2012. One of the candidates had no strong anion and was consequently eliminated, which left viridicatumtoxin as the only candidate (Figure 4b).

Figure 4. Dereplication of the $P$. brasilianum extract (a) UHPLC chromatogram of the active SAX fraction that contained the acidic compounds as well as UV and MS spectra of the potential candidates; (b) Hits in Antibase2012.

(a)

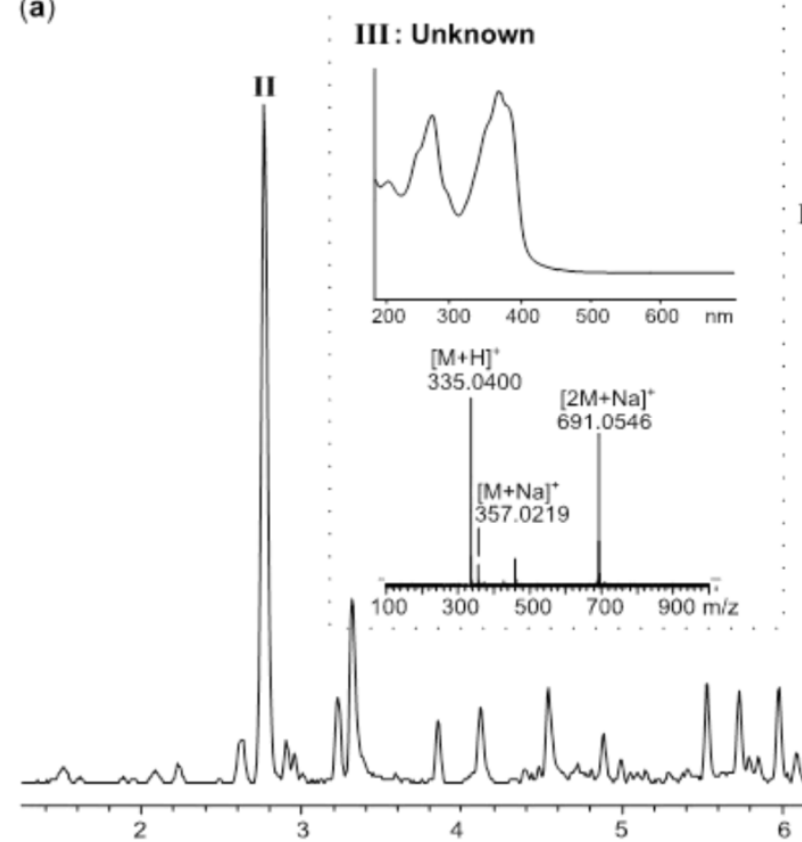

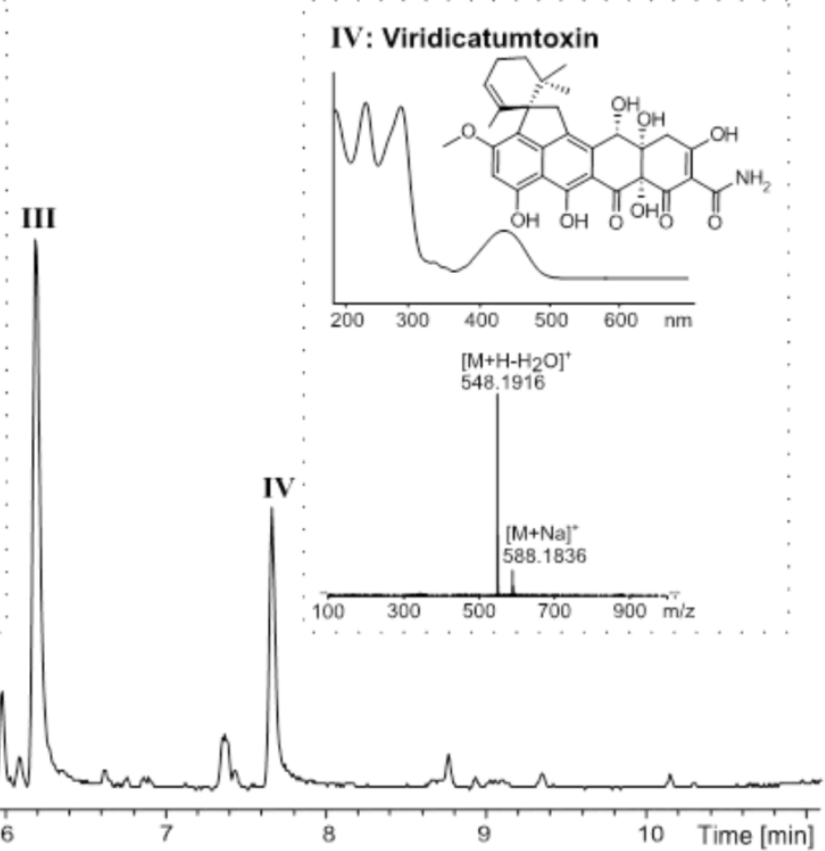

(b)

\begin{tabular}{|l|c|l|l|l|}
\hline \multicolumn{2}{|l|}{ III: Unknown } & & \multicolumn{2}{l|}{ IV: Viridicatumtoxin } \\
\hline Query & No. of candidates & & Query & No. of candidates \\
\hline $\mathrm{C}_{15} \mathrm{H}_{10} \mathrm{O}_{9}$ & 1 & & $\mathrm{C}_{30} \mathrm{H}_{31} \mathrm{NO}_{10}$ & 2 \\
\hline Strong anion & 0 & & Strong anion & 1 \\
\hline
\end{tabular}

The identity of viridicatumtoxin as compound IV was confirmed: (1) by comparison to the retention time and UV spectrum of an in-house standard; (2) by the fact that it held a strong anion; and (3) by having similar ${ }^{1} \mathrm{H}-\mathrm{NMR}$ chemical shifts as published for viridicatumtoxin [25]. Viridicatumtoxin was isolated as one of the most cytotoxic compounds tested towards CLL cells in this screening campaign with a median lethal concentrations $\left(\mathrm{LC}_{50}\right)$ value between 0.7 and $3.5 \mathrm{nM}$. Further testing revealed that the activity was not specific, as both CLL and stromal cells were targeted.

One flash fraction (70\% organic) from the $P$. decumbens (IBT 11843) extract was found active towards CLL cells $(\approx 200 \mathrm{ng} / \mathrm{mL})$. Further E-SPE analysis showed that the active compound was retained on SAX and MAX columns indicating the presence of a strong anion. By comparative dereplication tentative identifications of calbistrin A (Figure 5a) and B as well as their precursor (or decomposition product) versiol (Figure 5c) were established within the fraction. The MS based dereplication was complicated by the fact that the $[\mathrm{M}+\mathrm{H}]^{+}$ion was absent in the mass spectra of calbistrin $\mathrm{A}$ and $\mathrm{B}$. The presences of strong adduct- and fragmentation patterns consisting of the sodiated, $[\mathrm{M}+\mathrm{Na}]^{+}$, and the ammoniated, $\left[\mathrm{M}+\mathrm{NH}_{4}\right]^{+}$, adducts as well as neutral loss of one and two 
water molecules assisted the establishment of the monoisotopic masses and hereby the molecular formulas of calbistrin A and B. The identity of calbistrin A was confirmed by the presence of a carboxylic acid and by comparison of retention time and UV spectrum to an in-house standard. The tentative identity of calbistrin B was confirmed by comparison of the UV spectrum to that of calbistrin A (Figure 5a). Testing of calbistrin A from our in-house metabolite collection showed general cytotoxic activity towards CLL and healthy cells. Comparative experiments with calbistrin C (Figure 5b) from the metabolite collection did not induce cell death, indicating that the pharmacophore is located in the versiol part (Figure 5c) of the molecule.

Figure 5. Structure of (a) Calbistrin A, (b) Calbistrin C, and (c) Versiol.

(a)

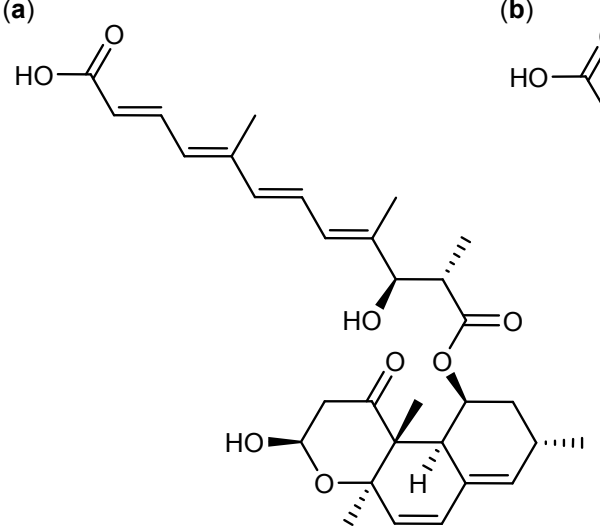

(b)

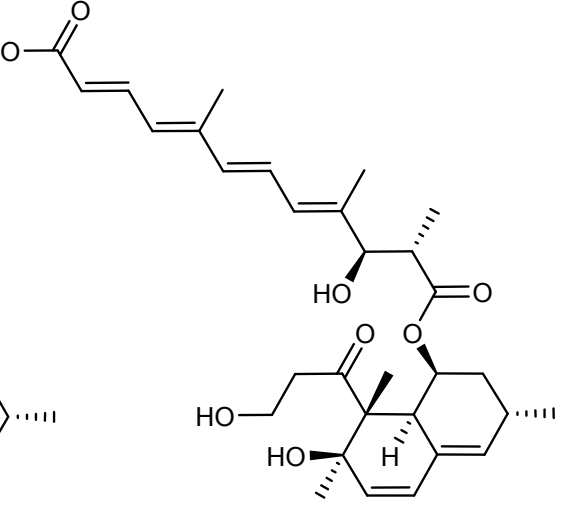

(c)

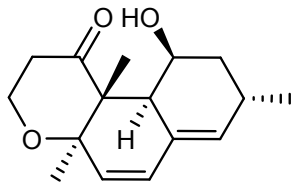

A bioactive flash fraction (activity approx. $100 \mathrm{ng} / \mathrm{mL}$ ) from a Penicillium cluniae (IBT 21051) extract was likewise subjected to E-SPE. Here, the bioactivity profiled revealed that the active compound was a medium to apolar compound with no charged functionalities. By comparative dereplication, the active compound was tentatively identified as brefeldin A (Figure 6a), which was in accordance with the profile revealed by E-SPE. The identity of brefeldin A was confirmed by its retention time and UV spectrum compared to an in-house standard. Brefeldin A is a known anticancer compound $[5,26]$ and commercially available, thus the activity was easily confirmed in the CLL assay. The compound displayed general cytotoxic activity for CLL cells $(0.39-1.56 \mu \mathrm{M})$ and stromal cells.

Figure 6. Examples of E-SPE and comparative dereplication (a) Brefeldin produced by P. cluniae, (b) Emestrin A produced by Aspergillus sp. (Emericella-like state), and (c) Neosolaniol monoacetate produced by $F$. compactum.

(a)<smiles>C[C@H](O)/C=C/C(=O)O[C@H](C)CCC/C=C/[C@H]1C[C@H](O)C[C@H]1O</smiles>

(b)

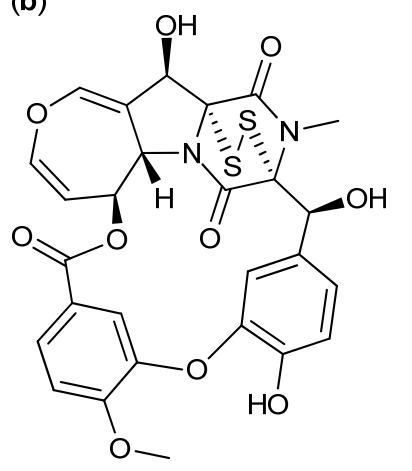

(c)

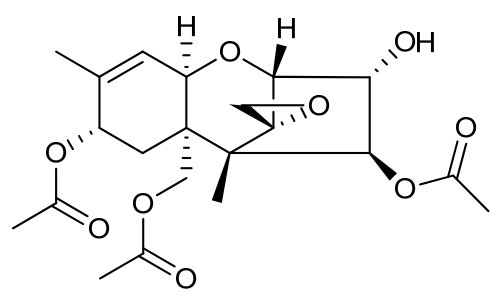


The E-SPE strategy of the bioactive extract $(\approx 40 \mathrm{ng} / \mathrm{mL})$ from Aspergillus sp. (Emericella-like state, IBT 22838) resulted in retention of the bioactive compound on the amino normal phase SPE column. Fast comparative dereplication based on UV spectra and retention times of in-house standards as well as comparison of ${ }^{1} \mathrm{H}-\mathrm{NMR}$ chemical shifts [27] led to an identification of the known antifungal and anticancer compound, emestrin A (Figure 6b) [5,28,29]. The pure emestrin A isolated form the active fractions showed cytotoxic activity towards CLL cells and stromal cells at the same concentration levels. Accordingly, emestrin A is regarded as a generally cytotoxic compound with no therapeutic window [30]. No further work was pursued on the Aspergillus sp. (Emericella-like state) extract.

The last example of bio-guided isolation based on E-SPE is demonstrated by the $F$. compactum (IBT 9034) extract with an activity at approximately $200 \mathrm{ng} / \mathrm{mL}$. The bioactive compound from $F$. compactum was retained on both the diol and amino columns in the E-SPE pre-fractionation experiment. Comparative dereplication revealed only one candidate that might be responsible for the activity. The compound was tentatively identified as the known trichothecene, neosolaniol monoacetate (Figure 6c). The compound was isolated and the ${ }^{1} \mathrm{H}-\mathrm{NMR}$ data was compared to the literature for final identification of neosolaniol monoacetate [31]. Neosolaniol monoacetate was tested in the CLL assay and found as a generally cytotoxic why no further work was performed on the $F$. compactum extract. The E-SPE approach with the optimized collection of ion-exchangers and normal phase SPE columns has turned out to be a good combination to evaluate and follow bioactivity of fungal extracts.

\subsection{Biological Structure-Activity Relationship of Ophiobolins}

The bioactive extract from a new species in Aspergillus section Usti (IBT 18591) was more selective than the above mentioned active extracts and in consequence selected for more detailed investigations. MS- and UV-based dereplication led to the tentative identification of the ophiobolin family of compounds. Ophiobolin K and 6-epiophiobolin K (Figure 7) [32] were isolated and ophiobolin $\mathrm{K}$ was found very potent against CLL cells in vitro.

The ophiobolins are a family of naturally occurring sesterterpenoids, currently comprising more than 35 known analogues [33-37]. They all consist of a $\mathrm{C}_{25}$ skeleton with a dicyclopenta[a,d]cyclooctane ring system. Some ophiobolins have an extra ring incorporated, as observed in ophiobolin A and $\mathrm{H}$ (Figure 7), forming two different types of tetra-cyclic structures [38]. The absolute configuration of ophiobolin A and G have been determined by X-ray crystallography [39,40] and the conformations of all stereocenters except $\mathrm{C} 6$ is expected to be conserved based on the biosynthetic production of ophiobolins demonstrated by the first sesterterpene synthase described in 2013 [41]. Ophiobolins exhibit a broad spectrum of inhibitory activity against cancer cell lines, including lung cancer A549, breast cancer MCF7, colon cancer HT29, melanoma Mel20, leukemia P388 and L1210 cell lines [5,34,35,42-45].

Further investigations of the anti-leukemic activity and pharmacophore of the ophiobolins in the CLL/stromal cell co-culture platform were performed with the purpose of isolating a high number of naturally occurring analogs as well as identification of novel analogues. Taking advantage of the huge biodiversity available in the IBT culture collection [19], we expanded the biodiversity and hereby the expected chemodiversity with 12 closely related Aspergilli from the section Usti (Table S7) [46]. Cultures of the 12 new strains were extracted in micro-scale [22] to explore their potential for 
producing ophiobolins. A. insuetus (IBT 28266) and A. calidoustus (IBT 25726) were identified as potent ophiobolin producers with one likely novel and more known ophiobolins analogs compared to the original strain (Figure 8).

The novel ophiobolin U (Figure 9) was isolated together with ophiobolin H [40] (Figure 7) and the rare 6-epiophiobolin N [43] (Figure 7) from the A. insuetus extract, while ophiobolin C [47] (Figure 7) and 6-epiophiobolin G [43] (Figure 7) were isolated from the A. calidoustus extract.

The structure of the novel ophiobolin $U$ was elucidated by 1D and 2D NMR spectroscopy. The ${ }^{1} \mathrm{H}-\mathrm{NMR}$ spectrum of ophiobolin $\mathrm{U}$ was closely related to that of ophiobolin $\mathrm{K}$ with many practically identical chemical shifts (Table S8 and S9). The most remarkable difference between ophiobolin U and ophiobolin K was found at C5 that shifted 143.9 ppm upfield from 217.0 to $73.1 \mathrm{ppm}$ in the carbon spectrum, indicating the disappearance of a ketone group. C5 had an additional HSQC correlation to a signal at $4.91 \mathrm{ppm}$ (H5). This significant change indicated a reduction of the ketone (C5) in ophiobolin $\mathrm{K}$ to a secondary alcohol in ophiobolin $\mathrm{U}$. This reduction was confirmed by the identification of a COSY spin system between H1-H2-H6 in ophiobolin $\mathrm{K}$ that in ophiobolin $\mathrm{U}$ was expanded with a vicinal coupling between the protons at 3.02 (H6) and 4.91 (H5) and further a vicinal coupling between $\mathrm{H} 5$ and the diastereotopic protons at 1.87 (H4a) and $2.68 \mathrm{ppm}(\mathrm{H} 4 \mathrm{~b})$ (Figure 10a).

Figure 7. Structures of ophiobolin A, 3-anhydro-ophiobolin A, 3-anhydro-6-epiophiobolin A, ophiobolin B, ophiobolin C, 6-epiophiobolin G, ophiobolin H, 6-epiophiobolin K, ophiobolin K, 6-epiophiobolin N, and ophiobolin U.

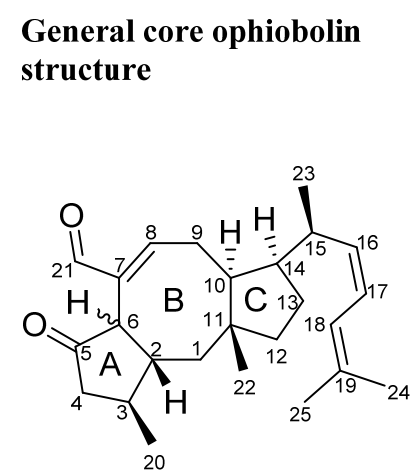

Ophiobolin B

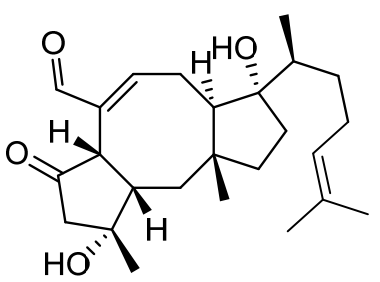

6-epiophiobolin K

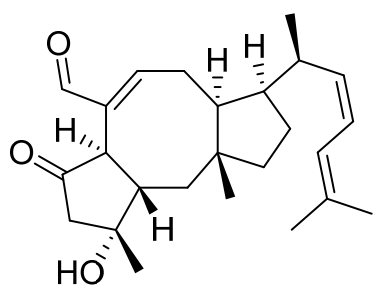

Ophiobolin A

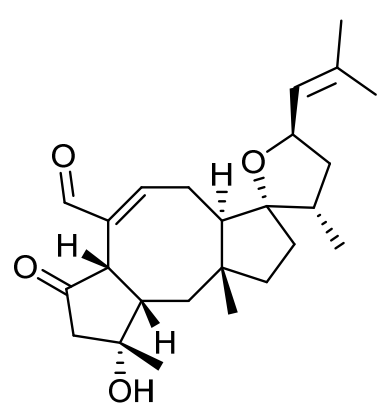

Ophiobolin C

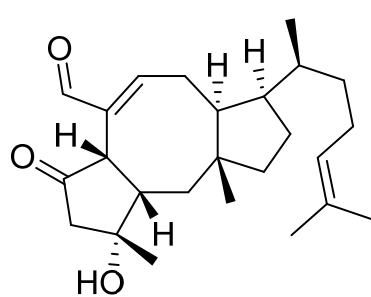

Ophiobolin K

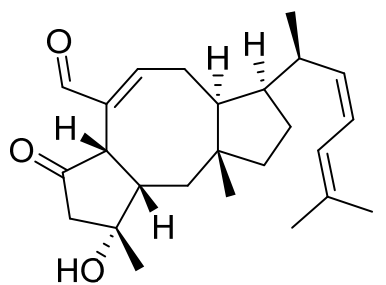

3-anhydro-ophiobolin A

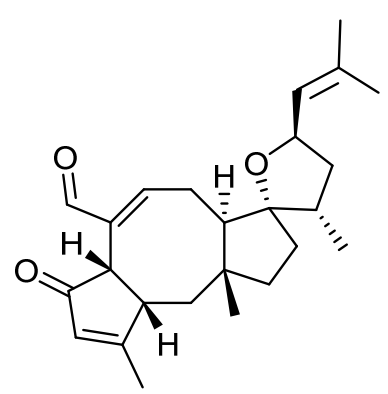

6-epiophiobolin G

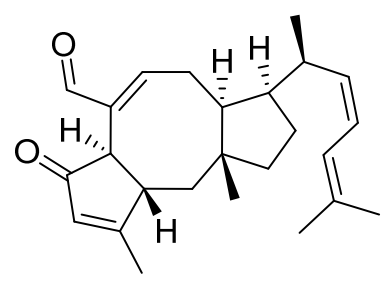

6-epiophiobolin $\mathbf{N}$

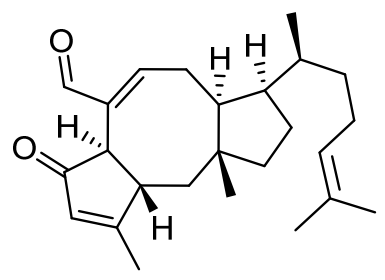

3-anhydro-6-epiophiobolin A<smiles>CC(C)=C[C@@H]1C[C@H](C)[C@]2(CC[C@@]3(C)C[C@@H]4C(C)=CC(=O)[C@H]4/C(C=O)=C/C[C@@H]32)O1</smiles>

Ophiobolin H

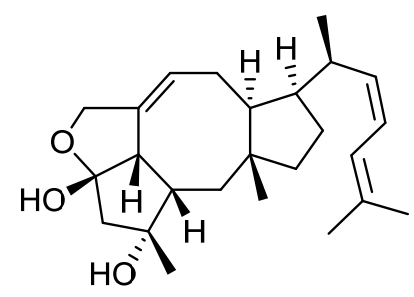

Ophiobolin U

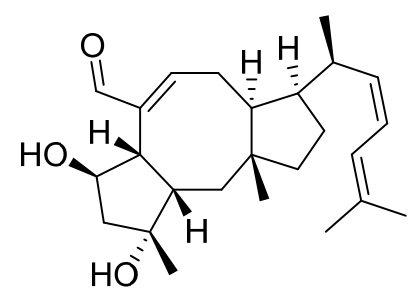


Figure 8. UHPLC chromatograms of (a) the new species in Aspergillus section Usti (IBT 18591) producing ophiobolin $\mathrm{K}$ and 6-epiophiobolin K, (b) A. insuetus (IBT 28266) producing the novel ophiobolin $\mathrm{U}$ together with ophiobolin $\mathrm{H}, \mathrm{K}, \mathrm{C}$ as well as 6-epiophiobolin $\mathrm{K}$ and $\mathrm{N}$ and (c) A. calidoustus (IBT 25726) producing ophiobolin $\mathrm{K}$ and $\mathrm{C}$ as well as 6-epiophiobolin $\mathrm{K}$ and $\mathrm{G}$.

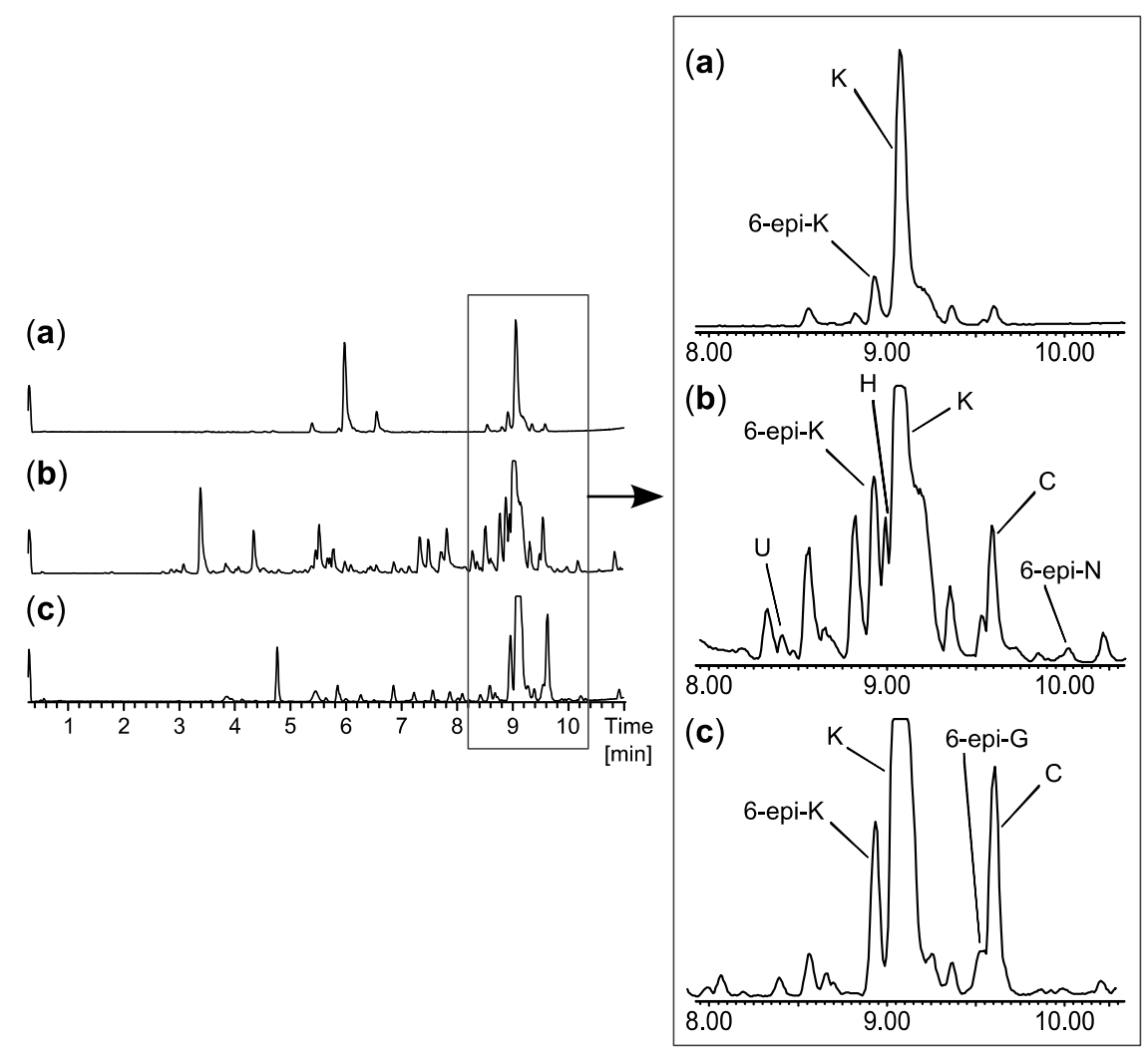

Figure 9. Structure of ophiobolin U.

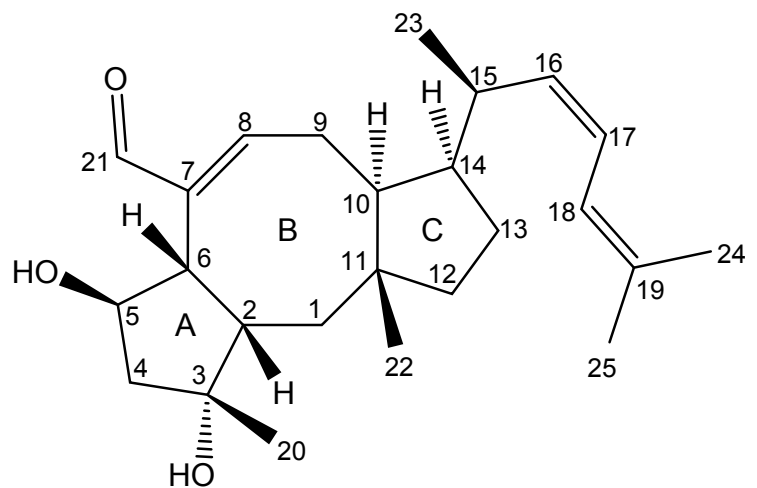

The spin systems identified in the DQF-COSY spectrum of ophiobolin U were assembled through HMBC correlations, which also enabled the identification of the quaternary carbon atoms. The most important HMBC correlations are shown in Figure 10b. The COSY spin systems were connected by HMBC connectivities further confirming the presence of the eight-membered ring. HMBC connectivities were found from H5 to the quaternary carbons at 81.9 (C3) and $142.1 \mathrm{ppm}(\mathrm{C} 7)$, from the diastereotopic protons at 1.03 (H1a) and $1.58 \mathrm{ppm}(\mathrm{H} 1 \mathrm{~b})$ to $\mathrm{C} 3$ and the carbon at $54.0 \mathrm{ppm}(\mathrm{C} 10)$, and finally from $\mathrm{H} 9$ to $\mathrm{C} 7$ and the quaternary carbon at $44.1 \mathrm{ppm}(\mathrm{C} 11)$. The reduction at $\mathrm{C} 5$ changed 
the chemical environment of the surrounding carbons $(\mathrm{C} 2, \mathrm{C} 3, \mathrm{C} 6, \mathrm{C} 8$ and $\mathrm{C} 21)$ that were more deshielded and therefore shifted 1.8-6.5 ppm downfield compared to ophiobolin K (Table S8). The remaining chemical shifts in ophiobolin $U$ matched the chemical shifts of ophiobolin K (Tables S8 and S9).

Figure 10. (a) Important DQF-COSY couplings and (b) important HMBC connectivities in the novel compound ophiobolin $U$.

(a)

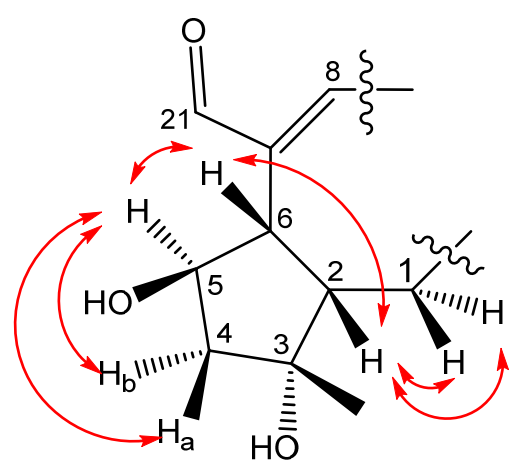

(b)

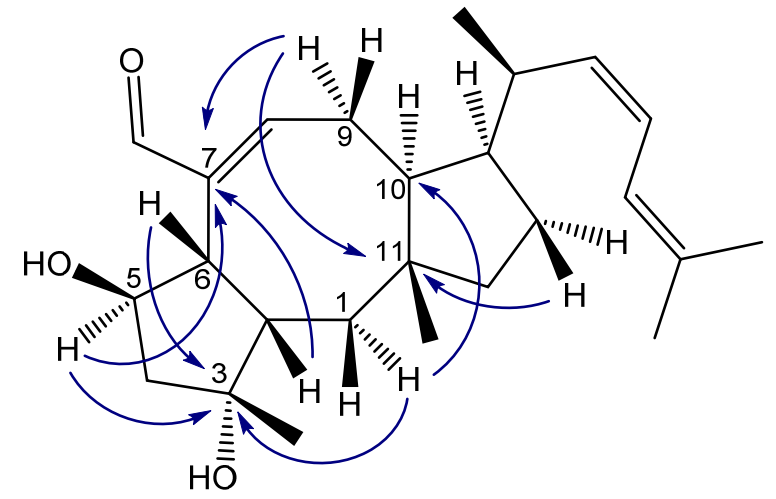

The stereochemistry of the A/B ring system in ophiobolin U (Figure 9) was assigned based on NOE correlations and chemical shifts. The A/B-cis ring system was established by the NOE correlations found between the protons at $2.30(\mathrm{H} 2)$ and $3.02 \mathrm{ppm}(\mathrm{H} 6)$, as demonstrated in Figure 11. The stereochemistry of C-5 was tentatively assigned through strong NOE correlations of the diastereotopic protons at $1.87(\mathrm{H} 4 \mathrm{a})$ and $2.68 \mathrm{ppm}(\mathrm{H} 4 \mathrm{~b})$. H4a had NOE correlations to the protons at $1.26 \mathrm{ppm}$ ( $\mathrm{H} 20)$ and $\mathrm{H} 2$, while $\mathrm{H} 4 \mathrm{~b}$ had a NOE correlation to $\mathrm{H} 5$, which indicated that the hydroxy group at $\mathrm{C} 5$ was cis to H6. Other important NOE correlations are shown in Figure 11.

Figure 11. Important NOE correlations in ophiobolin U.

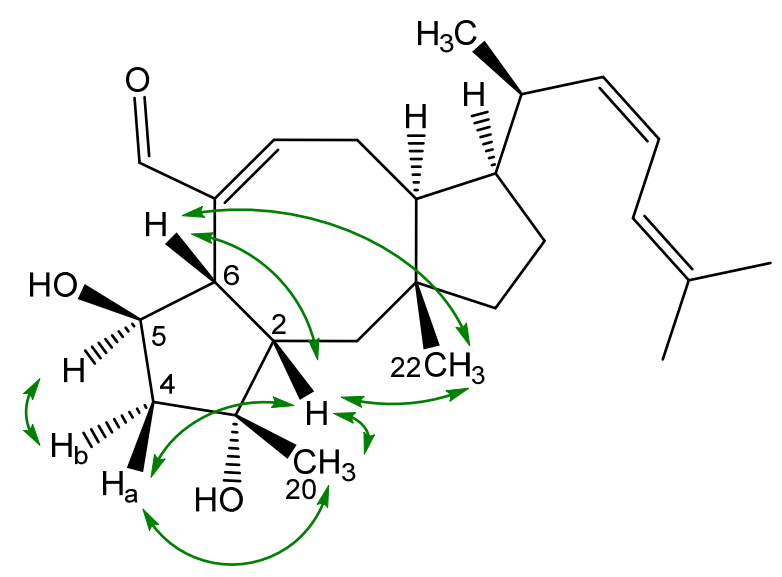

The A/B-cis was confirmed by chemical shifts. Earlier reports showed that $\mathrm{C} 1$ and $\mathrm{C} 22$ in ophiobolins with A/B-cis ring structure are more upfield compared to ophiobolins with A/B-trans ring structure [48]. In ophiobolin $U$ and ophiobolin $\mathrm{K}$, the chemical shifts of $\mathrm{C} 1$ and $\mathrm{C} 22$ were more upfield compared to 6-epiophiobolin $\mathrm{K}$, which indicate a A/B-cis ring structure in ophiobolin $\mathrm{U}$. Other reports have showed that the A/B-cis ring structure in ophiobolins causes a small deshielding $(0.2-0.3 \mathrm{ppm})$ 
for $\mathrm{H} 2$ and $\mathrm{H} 8$ as well as a small shielding (0.3-0.6 ppm) for $\mathrm{H} 4$ [49]. The ${ }^{1} \mathrm{H}$ chemical shifts for ophiobolin $U$ were inconclusive regarding conformation of the $\mathrm{A} / \mathrm{B}$ ring system. The residual stereocenters of ophiobolin $U$ were the same as in the known ophiobolins due to the stereospecificity of the biosynthetic pathway of the ophiobolins $[41,50]$.

The stereochemistry of the $\mathrm{A} / \mathrm{B}$ ring system of the remaining six ophiobolins (ophiobolin $\mathrm{K}$, 6-epiophiobolin K, 6-epiophiobolin N, 6-epiophiobolin G, ophiobolin H, and ophiobolin C) isolated in this study were confirmed by NOE correlations. Together with the general trend that $\mathrm{C} 1$ and $\mathrm{C} 22$ in the ophiobolins with A/B-cis ring structure were more upfield compared to ophiobolins with A/B-trans ring structure $[43,48]$. The shifting of chemical shifts for $\mathrm{H} 2, \mathrm{H} 4$, and $\mathrm{H} 8$ for the A/B-cis ring system were more ambiguous due to the small deshielding/shielding in chemical shifts and inconclusive for the seven ophiobolins. A comparison of the ${ }^{13} \mathrm{C}$ and ${ }^{1} \mathrm{H}$ chemical shifts of all the seven ophiobolins are found in Tables S8 and S9, respectively.

Besides the seven purified ophiobolins: ophiobolin A, ophiobolin B, 3-anhydroophiobolin A, and 3-anhydro-6-epiophiobolin A (Figure 7) were bought as standards with the aim of obtaining a broader understanding of the SAR of the ophiobolin family against CLL cells. Ophiobolin U was unstable and therefore not applied in any bioassay, but the remaining ten ophiobolins were tested for their cytotoxic activity towards CLL cells. Ophiobolin A, B, C, and $\mathrm{K}$ showed the strongest effects with $\mathrm{LC}_{50}$ values between 1 and $8 \mathrm{nM}$ (results compiled in Table 1 and Figure 12a). Testing of normal lung fibroblasts revealed that ophiobolin A and B displayed cytotoxic effects at $10 \mathrm{nM}$ concentration indicating a slight difference in bio-activity for CLL cells in comparison to healthy fibroblasts. Ophiobolin $\mathrm{C}$ and $\mathrm{K}$ displayed no effect towards normal lung fibroblasts in concentrations up to $10 \mathrm{nM}$ (Figure S17). Interestingly, 3-anhydroophiobolin A, 3-anhydro-6-epiophiobolin A, 6-epiophiobolin G, ophiobolin H, 6-epiophiobolin $\mathrm{K}$, and 6-epiophiobolin $\mathrm{N}$ exhibited low or no activity towards CLL cells. In fact, 6-epiophiobolin $\mathrm{K}$ targeted CLL cell viability only when applied at a 100-fold higher concentration than ophiobolin K (Figure 12b). Ophiobolin-treated cells were further stained with PE-labelled Annexin-V and 7-AAD, or antibodies for activated caspase-3 prior to flow cytometric analyses. Thereby, apoptosis was identified as the mode of killing of CLL cells as demonstrated recently for chaetoglobosin A [15].

Table 1. Apoptosis inducing activity $\left(\mathrm{LC}_{50}[\mathrm{nM}]\right)$ of the 10 ophiobolins towards CLL cells.

\begin{tabular}{cc}
\hline Compound & LC $_{\mathbf{5 0}}$ \\
\hline Ophiobolin A & $1 \mathrm{nM}$ \\
3-anhydro-ophiobolin A & Inactive \\
3-anhydro-6-epiophiobolin A & Inactive \\
Ophiobolin B & $2 \mathrm{nM}$ \\
Ophiobolin C & $8 \mathrm{nM}$ \\
6-epiophiobolin G & Inactive \\
Ophiobolin H & Inactive \\
Ophiobolin K & $4 \mathrm{nM}$ \\
6-epiophiobolin K & Inactive \\
6-epiophiobolin H & Inactive \\
\hline
\end{tabular}


Figure 12. Effects of different ophiobolins on CLL cell viability. (a) CLL cells cultured in HS-5 conditioned media were treated for $24 \mathrm{~h}$ with increasing concentrations of ophiobolin A, ophiobolin B, ophiobolin $\mathrm{C}$, ophiobolin $\mathrm{K}$, and 6-epiophiobolin $\mathrm{K}$, and cell viability was analyzed by CellTiter-Glo ${ }^{\circledR}$ assay measuring each data point as duplicate. Relative cell viability compared to DMSO control $(0.1 \%)$ is depicted as mean values $+\mathrm{SD}$ of 3 independent CLL samples; (b) As 6-epiophiobolin $\mathrm{K}$ treatment did not decrease cell viability in the concentration range tested in (a), CLL cells were treated with up to $900 \mathrm{nM}$ of 6-epiophiobolin $\mathrm{K}$, and cell viability was determined and compared to the active ophiobolin $\mathrm{B}$.

(a)

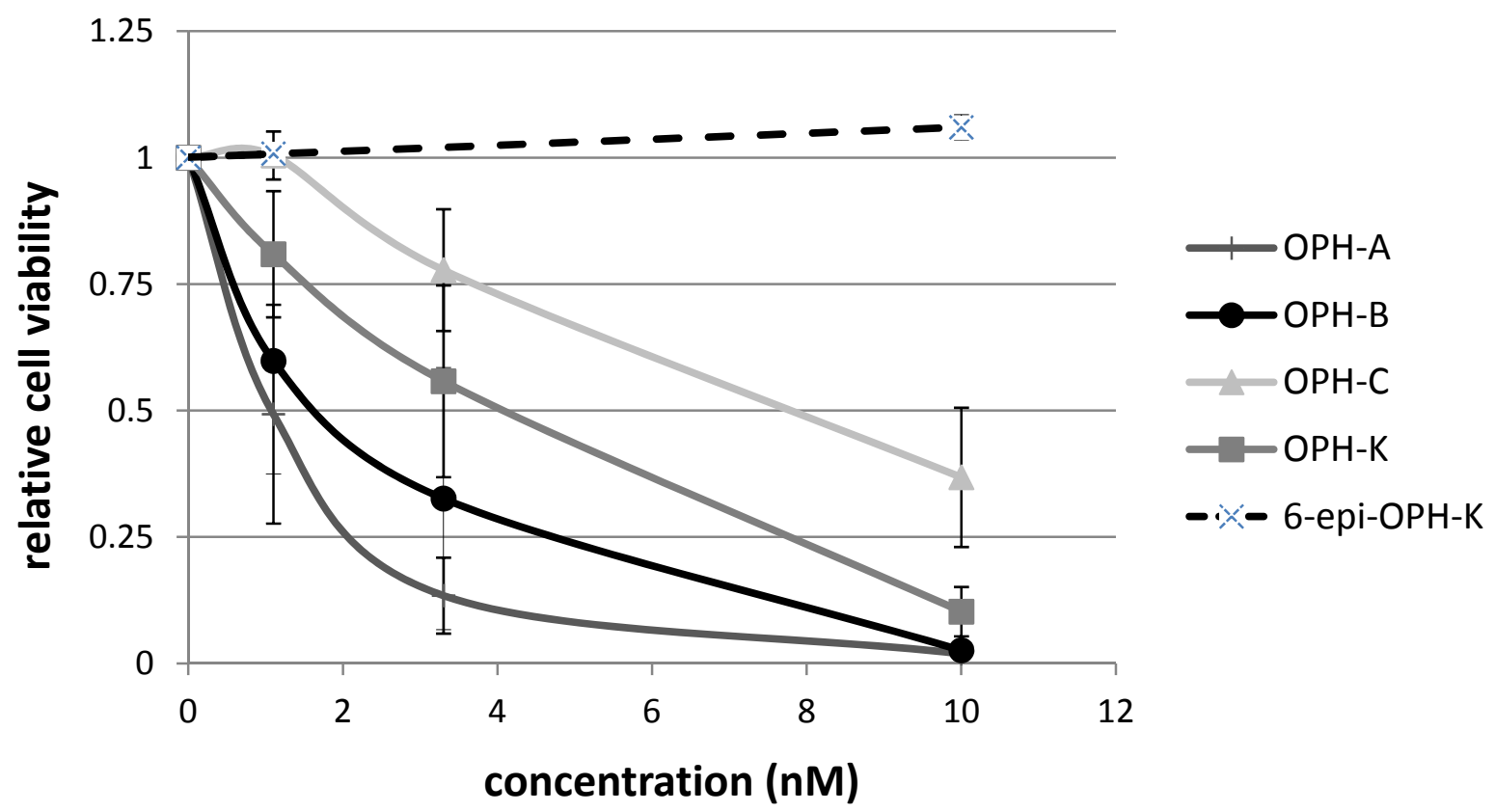

(b)

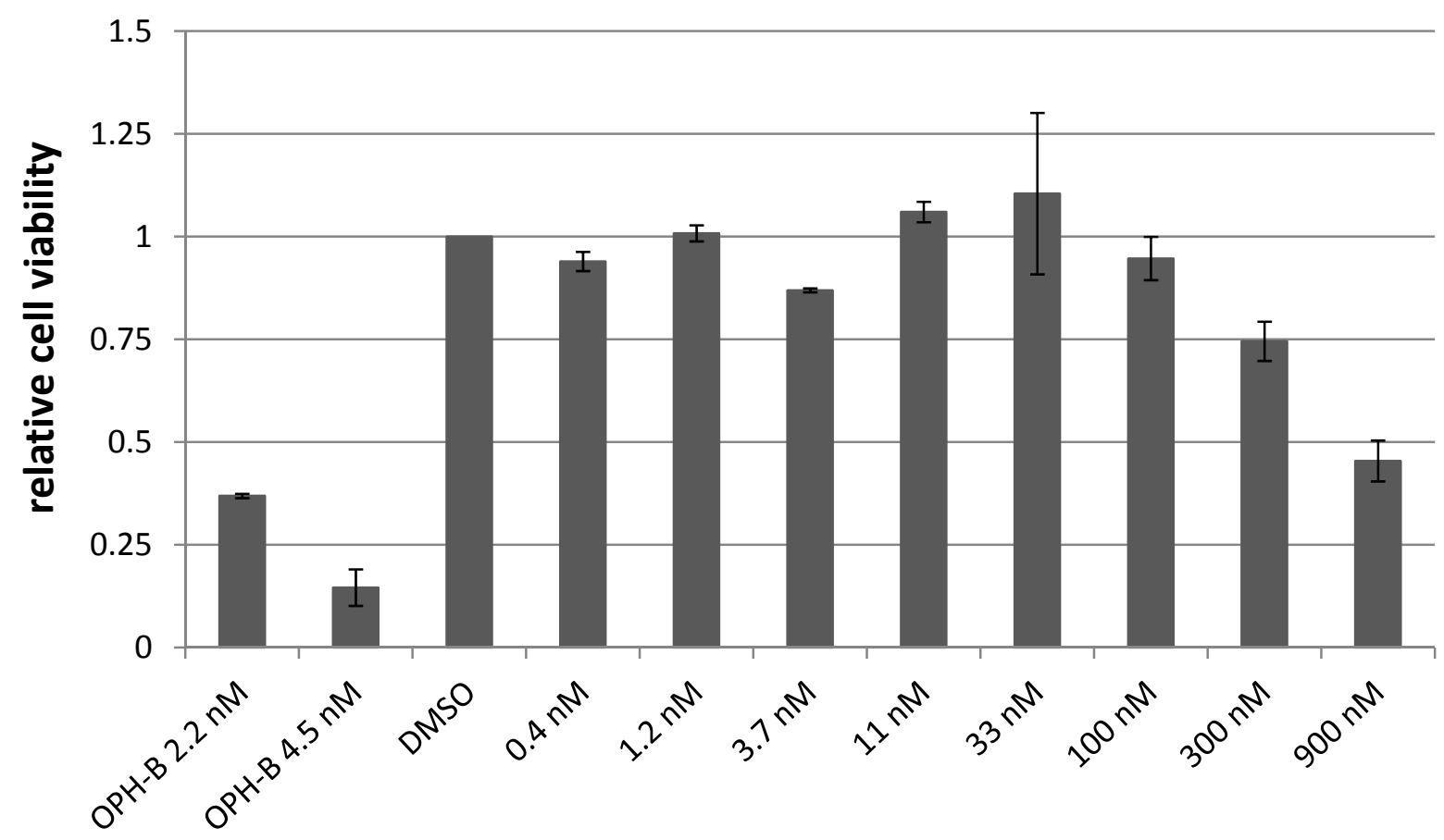


The results displayed in Table 1 and Figure 12a indicates that presence of a hydroxy group at C3 and an aldehyde at C21 is crucial for the activity of the ophiobolins. Our findings are thus in agreement with previous studies that have shown that these two groups covalently bind to calmodulin $[51,52]$. None of the 6-epiophiobolins tested were active against the CLL cells. To earn a broader understanding of the importance of this small steric change at C6, 3D-modeling of ophiobolin $\mathrm{K}$ (blue) and 6-epiophiobolin $\mathrm{K}$ (red) were done to give a visual representation of their lowest energy conformations (Figure 13).

Figure 13. Modulated 3D structures of ophiobolin K (blue) and 6-epiophiobolin K (red) in their lowest energy conformations overlaid. H6 protons are marked in ophiobolin K (cyan) and 6-epiophiobolin $\mathrm{K}$ (orange). The chain extending from $\mathrm{C} 14$ in ring $\mathrm{C}$ is not displayed to get a better clarity of the structures (the cut-off point is marked with *).

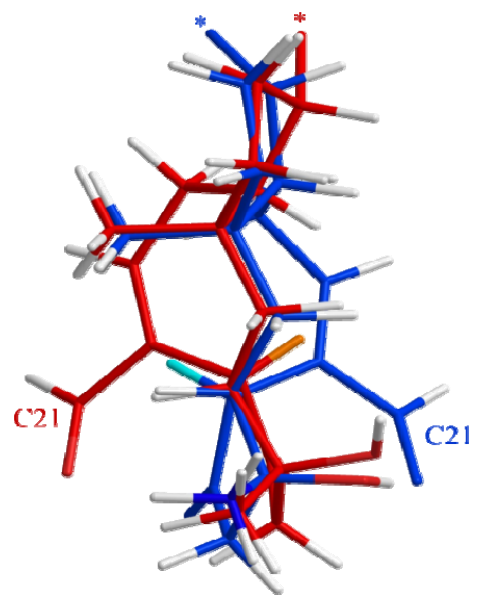

The difference in conformation between ophiobolin $\mathrm{K}$ and 6-epiophiobolin $\mathrm{K}$ involves a flipping of the eight-membered ring that result in a change of position of the $\mathrm{C} 21$ aldehyde from one to the other side of the plane observed in the figure. This conformational change is likely preventing the binding of calmodulin by the $\mathrm{C} 21$ aldehyde due to steric hindrance, resulting in the lack of activity for 6-epiophiobolin $\mathrm{K}$ contrasting ophiobolin $\mathrm{K}$.

\section{Experimental}

\subsection{General}

The fungal strains used are from the IBT culture collection at Department of Systems Biology, Technical University of Denmark. The LC-MS analyses were performed on a maXis quadrupole time of flight (qTOF) mass spectrometer (Bruker Daltonics, Bremen, Germany) with an electrospray ionization (ESI) ion source. The maXis was calibrated using sodium formate automatically infused prior to each analytical run, providing a mass accuracy of below $1 \mathrm{ppm}$. The mass spectrometer was linked to an Ultimate 3000 UHPLC system (Dionex, Sunnyvale, CA, USA) with DAD. Separation was achieved on a Kinetex $\mathrm{C}_{18}, 2.6 \mu \mathrm{m}, 2.1 \times 100 \mathrm{~mm}$ column (Phenomenex, Torrance, CA, USA) with a flow of $0.4 \mathrm{~mL} \mathrm{~min}^{-1}$ at $40{ }^{\circ} \mathrm{C}$ using a linear gradient $10 \%$ acetonitrile (ACN) in Milli-Q water (MQ) with $20 \mu \mathrm{M}$ formic acid (FA) going to $100 \% \mathrm{ACN}$ in $10 \mathrm{~min}$. All compounds were isolated by bioguided fractionation started by flash chromatography of the crude extracts, fractionated with an Isolera 
One automated flash system (Biotage, Uppsala, Sweden). The isolation of compounds were performed by a semi-preparative Gilson HPLC system (Middleton, WI, USA) with a 215 Liquid Handler, 819 Injection Module and a 172 DAD and fully controlled with Trilution LC software or on a Waters 600 chromatograph (Milford, MA, USA) attached to a Waters 600 DAD. One-dimensional and two-dimensional NMR experiments were acquired using standard pulse sequences on a $800 \mathrm{MHz}$ Bruker Avance spectrometer with a $5 \mathrm{~mm}$ TCI cryoprobe at the Danish Instrument Centre for NMR Spectroscopy of Biological Macromolecules at Carlsberg Laboratory, alternatively on a $500 \mathrm{MHz}$ Varian Unity Inova (Palo Alto, CA, USA) equipped with a HCP probe or a $400 \mathrm{MHz}$ Bruker Avance III equipped a BBO Prodigy cryoprobe NMR spectrometers.

\subsection{Micro Extraction for Initial Screen}

Two hundred and eighty nine (289) fungal extracts were prepared from cultivation of 137 fungal strains (Table S1). All extracts were prepared in accordance with the micro-extraction method developed by Smedsgaard [22]. Five plugs were collected across the colony. The samples were subsequently extracted using $(3: 2: 1 \mathrm{v} / \mathrm{v} / \mathrm{v})$ methanol $(\mathrm{MeOH})$, dichloromethane (DCM) and ethyl acetate (EtOAc) with $0.5 \%$ FA.

\subsection{Cultivation and Extraction}

The seven extracts described here were P. pulvillorum (IBT 22393), P. brasilianum (IBT 22244), P. decumbens (IBT 11843), P. cluniae (IBT 21051), Aspergillus sp. (Emericella-like state, IBT 22838), F. compactum (IBT 9034), and a new species in Aspergillus section Usti (IBT 18591). Each fungus was cultivated on 50 plates (media are listed in supplementary) for 8 days at $25^{\circ} \mathrm{C}$ in the dark with the exceptions of P. brasilianum. P. brasilianum (IBT 22244), A. insuetus (IBT 28266), and A. calidoustus (IBT 25726) were cultivated on 200 agar plates with Yeast Extract Sucrose (YES) for 14 days (except A. calidoustus that was incubated for 7 days) at $25{ }^{\circ} \mathrm{C}$ in the dark. All the fungi were extracted separately with EtOAc containing 1\% FA. Unwanted carbohydrates from the media as well as fatty acids were removed from the four large extract ( $P$. brasilianum, the new species in Aspergillus section Usti, A. insuetus, and A. calidoustus) by liquid-liquid extraction with water/ $\mathrm{MeOH}$ and heptane, respectively leaving the crude extracts.

\subsection{Bioassay-Guided Fractionation}

The crude extract of $P$. decumbens, P. pulvillorum, $P$. cluniae, Aspergillus sp. (Emericella-like state), and $F$. compactum were fractionated on a $\mathrm{RP}_{18}(25 \mathrm{~g}, 33 \mathrm{~mL})$ column flash column with at gradient of: $15 \%-100 \% \mathrm{ACN}$ in $20 \mathrm{~min}$ and flow rate $25 \mathrm{~mL} / \mathrm{min}$. No further fractionations were done with the bioactive flash fraction from the $P$. cluniae extract. Penicillic acid was purified from the bioactive flash fraction from the $P$. pulvillorum extract by semi-preparative HPLC LunaII $\mathrm{C}_{18}$ $(250 \times 10 \mathrm{~mm}, 5 \mu \mathrm{m})$ column with at gradient of: $15 \%-100 \% \mathrm{ACN}$ in $20 \mathrm{~min}$ and flow rate $5 \mathrm{~mL} / \mathrm{min}$. ACN and MQ were added $20 \mathrm{mM} F A$.

Penicillic acid: White solid; UV (ACN) $\lambda_{\max }$ : $227 \mathrm{~nm}$; HRMS $m / z 170.0573\left(\mathrm{M}^{+}\right.$calculated for $\mathrm{C}_{8} \mathrm{H}_{10} \mathrm{O}_{4}, m / z$ 170.0574; $\left.0.5 \mathrm{ppm}\right)$. 


\subsubsection{E-SPE}

P. brasilianum, P. decumbens, Aspergillus sp. (Emericella-like state), and F. compactum extracts were prefractionated analytical in accordance with the E-SPE method developed by Månsson et al. [21] with SAX, MAX, and SCX ion-exchanger SPE columns though without the Sephadex LH-20 column. Additionally two normal phase (amino and diol) columns were add to the setup. For each extract, $5 \mathrm{mg}$ was loaded on both the amino column $(100 \mathrm{mg}, 1 \mathrm{~mL})$ and the diol column $(100 \mathrm{mg}, 1 \mathrm{~mL})$. The compounds were eluted by 2 column volume (CV) heptane, 2 CV DCM, 2 CV DCM/EtOAc (1:1), $2 \mathrm{CV}$ EtOAc, $2 \mathrm{CV}$ EtOAc/MeOH, $2 \mathrm{CV} \mathrm{MeOH}, 4 \mathrm{CV}$ ACN, $2 \mathrm{CV}$ ACN/MQ + 2\% FA (75:25), 2 CV $\mathrm{ACN} / \mathrm{MQ}+2 \% \mathrm{FA}(50: 50), 2 \mathrm{CV}$ ACN/MQ + 2\% FA (25:75), $2 \mathrm{CV}$ ACN/MQ + 2\% FA (10:90). No further fractionations were done with the bioactive flash fraction from the $P$. decumbens extract.

The bioactive $\mathrm{C}_{18}$ flash fraction from the Aspergillus sp. (Emericella-like state) extract was loaded on the amino column $(10 \mathrm{~g}, 15 \mathrm{~mL})$ and eluted by $2 \mathrm{CV}$ heptane, $2 \mathrm{CV}$ DCM, $2 \mathrm{CV}$ DCM/EtOAc (1:1), 2 CV EtOAc, 2 CV EtOAc/MeOH, 2 CV MeOH, 4 CV ACN, 2 CV ACN/MQ + 2\% FA(75:25), $2 \mathrm{CV}$ ACN/MQ + 2\% FA (50:50), $2 \mathrm{CV}$ ACN/MQ + 2\% FA (25:75), 2 CV ACN/MQ + 2\% FA (10:90). Emestrin A (1.1 mg) was finally isolated by preparative HPLC on a LunaII $\mathrm{C}_{18}(250 \times 10 \mathrm{~mm}$, $5 \mu \mathrm{m}$ ) column with at gradient of: $50 \%-100 \%$ ACN in $20 \mathrm{~min}$ and flow rate $5 \mathrm{~mL} / \mathrm{min}$. ACN and MQ were added 50 ppm trifluoroacetic acid (TFA).

Emestrin A: White solid; $[\alpha]_{589.3 \mathrm{~nm}}$ : +22 ${ }^{\circ}$; UV (ACN) $\lambda_{\max }: 230$ (sh), 267 (sh), 285 (sh); HRMS $m / z$ $598.0713\left(\mathrm{M}^{+}\right.$calculated for $\mathrm{C}_{27} \mathrm{H}_{22} \mathrm{~N}_{2} \mathrm{O}_{10} \mathrm{~S}_{2}, m / z$ 598.0711; $\left.0.4 \mathrm{ppm}\right)$.

The bioactive $\mathrm{C}_{18}$ flash fraction from the $F$. compactum extract was loaded on a diol column (10 $\mathrm{g}$, $15 \mathrm{~mL}$ ) and eluted by $2 \mathrm{CV}$ heptane, $2 \mathrm{CV}$ heptanes/DCM (1:1), 2 CV DCM, 2 CV DCM/EtOAc (1:1), $2 \mathrm{CV}$ EtoAc, $2 \mathrm{CV}$ EtOAc/MeOH, $2 \mathrm{CV}$ MeOH, $2 \mathrm{CV}$ MeOH/ACN (1:1) and $2 \mathrm{CV}$ ACN. Neosolaniol monoacetate was isolated with semi-preparative HPLC on a Luna II, $\mathrm{C}_{18}, 5 \mu \mathrm{m}, 10 \times 250 \mathrm{~mm}$ column with $30 \%-70 \% \mathrm{ACN}$ in $20 \mathrm{~min}$ and flow rate $5 \mathrm{~mL} / \mathrm{min}$. ACN and MQ were added $20 \mathrm{mM} \mathrm{FA}$.

Neosolaniol monoacetate: White solid; HRMS $m / z 424.1728\left(\mathrm{M}^{+}\right.$calculated for $\mathrm{C}_{21} \mathrm{H}_{28} \mathrm{O}_{9}, \mathrm{~m} / \mathrm{z}$ 424.1728; 0 ppm).

The crude extract of $P$. brasilianum was loaded on a SAX column (100 g, $132 \mathrm{~mL})$ and washed by $1 \mathrm{CV} 70 \% \mathrm{MeOH}$ in $\mathrm{MQ}(\mathrm{pH} \mathrm{11)}$ and $1 \mathrm{CV} 100 \% \mathrm{MeOH}(\mathrm{pH} 7)$ giving the SAX-1 fraction. Subsequently eluted by $2 \mathrm{CV} 100 \% \mathrm{MeOH}(\mathrm{pH}$ 2) giving the SAX-2 fraction. Viridicatumtoxin was isolated $\left(27.5 \mathrm{mg}\right.$ ) from SAX-2 on a RP $\mathrm{C}_{18}$ column with at gradient of: $30 \%-100 \% \mathrm{ACN}$ in $60 \mathrm{~min}$ and flow rate $40 \mathrm{~mL} / \mathrm{min}$. ACN and MQ were added $50 \mathrm{ppm}$ TFA.

Viridicatumtoxin: Yellow solid; UV (ACN) $\lambda_{\max }$ : 238, 286, $435 \mathrm{~nm}$; HRMS m/z $565.1942\left(\mathrm{M}^{+}\right.$ calculated for $\mathrm{C}_{30} \mathrm{H}_{31} \mathrm{NO}_{10}, \mathrm{~m} / z$ 565.1942; 0 ppm).

\subsubsection{Ophiobolins}

The crude extract of a new species in Aspergillus section Usti (IBT 18591) was fractionated on a RP $\mathrm{C}_{18}(25 \mathrm{~g}, 33 \mathrm{~mL})$ flash column with at gradient of: $15 \%-100 \% \mathrm{ACN}$ in $20 \mathrm{~min}$ and flow rate 
$25 \mathrm{~mL} / \mathrm{min}$. Subsequently the active fraction was loaded on a diol flash column and eluted with $2 \mathrm{CV}$ heptane, 2 CV heptanes/DCM (1:1), 2 CV DCM, 2 CV EtOAc, 2 CV MeOH. Ophiobolin K and 6-epiophiobolin $\mathrm{K}$ were isolated from the active fraction by semi-preparative HPLC on a Luna II, $\mathrm{C}_{18}$, $5 \mu \mathrm{m}, 10 \times 250 \mathrm{~mm}$ column by $70 \%-100 \% \mathrm{ACN}$ in $25 \mathrm{~min}$ and flow rate $5 \mathrm{~mL} / \mathrm{min}$.

Ophiobolin K: White solid; $[\alpha]_{589.3 \mathrm{~nm}}:+161^{\circ}$; UV (ACN) $\lambda_{\max }: 241 \mathrm{~nm}$; HRMS m/z $384.2658\left(\mathrm{M}^{+}\right.$ calculated for $\mathrm{C}_{25} \mathrm{H}_{36} \mathrm{O}_{3}, \mathrm{~m} / z$ 384.2659; $\left.0.3 \mathrm{ppm}\right) ;{ }^{13} \mathrm{C}$ - and ${ }^{1} \mathrm{H}-\mathrm{NMR}$ : see Tables S8 and S9, respectively.

6-Epiophiobolin K: White solid; $[\alpha]_{589.3 \mathrm{~nm}}$ : $+53^{\circ}$; UV (ACN) $\lambda_{\max }: 239 \mathrm{~nm}$; HRMS m/z $384.2658\left(\mathrm{M}^{+}\right.$ calculated for $\mathrm{C}_{25} \mathrm{H}_{36} \mathrm{O}_{3}, \mathrm{~m} / z$ 384.2659; $\left.0.3 \mathrm{ppm}\right) ;{ }^{13} \mathrm{C}$ - and ${ }^{1} \mathrm{H}-\mathrm{NMR}$ : see Tables S8 and S9, respectively.

The crude extract of $A$. insuetus (IBT 28266) was loaded on a diol flash column and eluted with $2 \times 2 \mathrm{CV}$ heptane, $2 \mathrm{CV}$ heptanes/DCM (1:1), $2 \mathrm{CV}$ DCM, $2 \mathrm{CV}$ EtOAc, $2 \mathrm{CV} \mathrm{MeOH}$. The active fraction was then loaded on a $\mathrm{RP} \mathrm{C}_{18}$ flash column with at gradient of: $80 \%-100 \% \mathrm{ACN}$ in $45 \mathrm{~min}$ and flow rate $40 \mathrm{~mL} / \mathrm{min}$. Ophiobolin $\mathrm{U}$, ophiobolin $\mathrm{H}$ and 6-epiophiobolin $\mathrm{N}$ were isolated from the active fraction by semi-preparative HPLC on a Gemini, $\mathrm{C}_{6}-\mathrm{Ph}, 5 \mu \mathrm{m}, 10 \times 250 \mathrm{~mm}$ column . Ophiobolin U was purified by $55 \%-70 \% \mathrm{ACN}$ in $25 \mathrm{~min}$ and flow rate $5 \mathrm{~mL} / \mathrm{min}$. Ophiobolin $\mathrm{H}$ and 6-epiophiobolin $\mathrm{N}$ were purified by 50\% ACN isocratic in $15 \mathrm{~min}$, then 50-60 min ACN in $15 \mathrm{~min}$, and then up to $100 \% \mathrm{ACN}$ in $5 \mathrm{~min}$. ACN and MQ were added 50 ppm TFA.

Ophiobolin $U$ : White solid; $[\alpha]_{589.3 \mathrm{~nm}}:+3^{\circ}$; UV (ACN) $\lambda_{\max }: 242 \mathrm{~nm}$; HRMS m/z $386.2813\left(\mathrm{M}^{+}\right.$ calculated for $\mathrm{C}_{25} \mathrm{H}_{38} \mathrm{O}_{3}, \mathrm{~m} / z$ 386.2816; $\left.0.5 \mathrm{ppm}\right) ;{ }^{1} \mathrm{H}-\mathrm{NMR}\left(800 \mathrm{MHz}, \mathrm{CDCl}_{3}\right): \delta 0.91(2 \mathrm{H}, \mathrm{d}, 6.7, \mathrm{H} 23)$, $0.99 \mathrm{~s}(3 \mathrm{H}, \mathrm{s}, \mathrm{H} 22), 1.03$ (1H, m, H1a), 1.26 (3H, s, H20), 1.38 (2H, m, H12), 1.55 (1H, m, H10), 1.58 (1H, m, H1b), 1.58 (1H, m, H13a), 1.74 (3H, s, H24), 1.78 (1H, m, H13b), 1.82 (3H, s, H25), 1.87 (1H, dd, 4.1, 15.1, H4a), 2.09 (1H, m, H14), 2.24 (1H, m, H9a), 2.30 (1H, m, H2), 2.68 (1H, dd, 7.9, 15.1, H4b), 2.72 (1H, m, H15), 2.89 (1H, dd, 8.5, 12.5, H9b), $3.02 \mathrm{~d}(1 \mathrm{H}, \mathrm{d}, 9.6, \mathrm{H} 6), 4.91$ (1H, dd, 4.7, 7.9, H5), $5.21(1 \mathrm{H}, \mathrm{t}, 10.0, \mathrm{H} 16), 6.00(1 \mathrm{H}, \mathrm{m}, \mathrm{H} 18), 6.03(1 \mathrm{H}, \mathrm{m}, \mathrm{H} 17), 6.94 \mathrm{t}(1 \mathrm{H}, \mathrm{d}, 8.5, \mathrm{H} 8)$, 9.26 (1H, s, H21); ${ }^{13} \mathrm{C}-\mathrm{NMR}\left(200 \mathrm{MHz}, \mathrm{CDCl}_{3}\right): \delta 18.3$ (C24), 18.6 (C22), 20.6 (C23), 25.6 (C9), 26.3 (C20), 26.7 (C13), 26.7 (C25), 35.2 (C1), 35.9 (C15), 42.0 (C12), 44.1 (C11), 47.4 (C14), 50.5 (C6), 51.0 (C2), 53.4 (C4), 54.0 (C10), 73.1 (C5), 81.9 (C3), 120.2 (C18), 122.3 (C17), 135.9 (C19), 137.7 (C16), 142.1 (C7), 164.1 (C8), 198.1 (C21). Full dataset is found in Table S10.

Ophiobolin H: White solid; [ $\alpha]_{589.3 \mathrm{~nm}}$ : $+60^{\circ}$; UV (ACN) $\lambda_{\max }: 241 \mathrm{~nm}$; HRMS $m / z 386.2817\left(\mathrm{M}^{+}\right.$calculated for $\mathrm{C}_{25} \mathrm{H}_{38} \mathrm{O}_{3}, m / z 386.2816$; $\left.-0.5 \mathrm{ppm}\right) ;{ }^{13} \mathrm{C}$ - and ${ }^{1} \mathrm{H}-\mathrm{NMR}$ : see Tables $\mathrm{S} 8$ and S9, respectively.

6-Epiophiobolin $N$ : White solid; $[\alpha]_{589.3 \mathrm{~nm}}$ : $+10^{\circ}$; UV (ACN) $\lambda_{\max }: 232 \mathrm{~nm}$; HRMS m/z $368.2711\left(\mathrm{M}^{+}\right.$ calculated for $\left.\mathrm{C}_{25} \mathrm{H}_{36} \mathrm{O}_{2}, m / z 368.2710 ;-0.2 \mathrm{ppm}\right) ;{ }^{13} \mathrm{C}$ - and ${ }^{1} \mathrm{H}-\mathrm{NMR}$ : see Tables $\mathrm{S} 8$ and $\mathrm{S} 9$, respectively.

The crude extract of $A$. calidoustus (IBT 25726) was loaded on a diol flash column and eluted with 2 CV heptane, 2 CV heptanes/DCM (1:1), 2 CV DCM, 2 CV EtOAc, 2 CV MeOH. Ophiobolin C and 6-epiophiobolin $\mathrm{G}$ were isolated from the active fraction by semi-preparative HPLC on a Luna II, $\mathrm{C}_{18}$, $5 \mu \mathrm{m}, 10 \times 250 \mathrm{~mm}$ column. Ophiobolin $\mathrm{C}$ was purified by $80 \% \mathrm{ACN}$ in MQ and 6-epiophiobolin $\mathrm{G}$ was purified by $80 \% \mathrm{MeOH}$ in MQ both isocratic with a flow rate of $5 \mathrm{~mL} / \mathrm{min}$. 
Ophiobolin C: White solid; $[\alpha]_{589.3 \mathrm{~nm}:}+298^{\circ}$; UV (ACN) $\lambda_{\max }: 240 \mathrm{~nm}$; HRMS m/z $386.2813\left(\mathrm{M}^{+}\right.$ calculated for $\mathrm{C}_{25} \mathrm{H}_{38} \mathrm{O}_{3}, m / z$ 386.2816; $\left.0.7 \mathrm{ppm}\right) ;{ }^{13} \mathrm{C}$ - and ${ }^{1} \mathrm{H}-\mathrm{NMR}$ : see Tables S8 and S9, respectively.

6-Epiophiobolin $G$ : White solid; $[\alpha]_{589.3 \mathrm{~nm}}:+127^{\circ}$; UV (ACN) $\lambda_{\max }: 234 \mathrm{~nm}$; HRMS $m / z 366.2553\left(\mathrm{M}^{+}\right.$ calculated for $\mathrm{C}_{25} \mathrm{H}_{34} \mathrm{O}_{2}, m / z$ 366.2554; $\left.0.1 \mathrm{ppm}\right) ;{ }^{13} \mathrm{C}$ - and ${ }^{1} \mathrm{H}-\mathrm{NMR}$ : see Tables S8 and S9, respectively.

\subsection{CLL Cells, Cell Viability and Apoptosis Assays}

Whole blood samples were obtained from patients that matched the standard diagnostic criteria for CLL after informed consent in accordance with the Declaration of Helsinki. All studies performed were approved by the ethics committee of the University of Ulm. Peripheral blood mononuclear cells (PBMC) were isolated by Ficoll density gradient and consisted of at least $80 \% \mathrm{CD}^{+} \mathrm{CD} 19^{+}$leukemic cells as determined by flow cytometry. For the initial screen, cocultures of HS- 5 stromal cells and CLL cells were established as previously described [53]. For retesting of bio-active substances, CLL cells were cultured in conditioned media of HS-5 cells, which was harvested after 3-4 days of culture and $80 \%$ confluency and depleted of HS- 5 cells and debris by centrifugation. CLL cells were seeded in duplicates at a density of $3 \times 10^{5}$ cells/well in opaque-walled 96-well plates. Fractions or pure compounds were added in different concentrations and incubated for 24 h. 0.1\% DMSO was used as a negative control. Cell viability was assessed using CellTiter-Glo ${ }^{\circledR}$ assay (Promega, Madison, WI, USA) according to manufacturer's protocol. Luminescence signals were recorded using a Mithras LB940 plate reader (Berthold Technologies, Bad Wildbad, Germany). Background signals of medium were subtracted from each well as described by Knudsen et al. [15].

Apoptotic cell death was detected by flow cytometry using Annexin V-phycoerythrin (PE) and 7-aminoactinomycin (7-AAD) staining kit (BD Biosciences, Heidelberg, Germany) as described by Seiffert et al. [12]. To confirm apoptosis induction, staining for active caspase 3 was performed after fixation and permeabilization of cells using BD Cytofix/Cytoperm ${ }^{\mathrm{TM}}$ solution as described by the manufacturer by using PE-conjugated anti-active caspase 3 antibodies (clone C92-605, BD Biosciences). All flow cytometry analyses were carried out using a FACSCanto II flow cytometer equipped with FACSDiva software (BD Biosciences).

\section{Conclusions}

In conclusion, our combined bio-guided and dereplication based discovery approach has proven to be effective for fast dereplication and discovery of bioactive fungal natural products that target CLL cells. Comparative testing of active extracts on CLL cells as well as healthy cells identified compounds with general and selective bioactivity. The ophiobolin family showed high activity for CLL cells. The known ophiobolins A, B, C and $\mathrm{K}$ induced apoptosis in CLL cells with $\mathrm{LC}_{50}$ values of 1, 2, 8, and $4 \mathrm{nM}$, respectively with a lower bioactivity for healthy fibroblasts. The high activities for CLL cells were found only in ophiobolins with a hydroxy group at $\mathrm{C} 3$, an aldehyde at $\mathrm{C} 21$, and A/B-cis ring structure. In the remaining six bioactive extracts, the compounds responsible for the activity were tentatively identified by dereplication, and the activities towards CLL cells were verified by testing the pure compounds. The six active compounds, penicillic acid, viridicatumtoxin, calbistrin A, brefeldin A, emestrin A, and neosolaniol monoacetate, were all known and generally cytotoxic. In order to identify 
substances that are of therapeutic value for cancer cells, selective active substances need to be retested on a large cohort of cancer and healthy cells. In general, cytotoxic compounds are only suitable as anti-cancer pharmaceuticals if they selectively target the cancer cells and not healthy cells, or at least have a higher impact on the tumor cells. Activity optimization is well exemplified with these studies demonstrating the great potential of looking into the chemistry of closely related species to obtain more analogue compounds of a promising scaffold.

\section{Supplementary Materials}

Supplementary materials can be accessed at: http://www.mdpi.com/1420-3049/18/12/14629/s1.

\section{Acknowledgments}

We acknowledge the support of The Danish Cancer Society grant \# R20-A1157-10-S2. This study was additionally supported by the Helmholtz Virtual Institute "Understanding and overcoming resistance to apoptosis and therapy in leukemia" and by the research project of the German Federal Ministry of Education and Research "CancerEpiSys". We thank the Danish Instrument Center for NMR Spectroscopy of Biological Macromolecules for NMR time. Furthermore, we thank Maria Månsson for critical proof reading of the manuscript and for suggestions and Sibylle Ohl for technical support.

\section{Conflicts of Interest}

The authors declare no conflict of interest.

\section{References}

1. Zenz, T.; Mertens, D.; Küppers, R.; Döhner, H.; Stilgenbauer, S. From pathogenesis to treatment of chronic lymphocytic leukaemia. Nat. Rev. Cancer 2010, 10, 37-50.

2. Burger, J.A.; Montserrat, E. Coming full circle: 70 years of chronic lymphocytic leukemia cell redistribution, from glucocorticoids to inhibitors of B-cell receptor signaling. Blood 2013, 121, 1501-1509.

3. Nielsen, K.F.; Månsson, M.; Rank, C.; Frisvad, J.C.; Larsen, T.O. Dereplication of microbial natural products by LC-DAD-TOFMS. J. Nat. Prod. 2011, 74, 2338-2348.

4. Frisvad, J.C.; Smedsgaard, J.; Larsen, T.O.; Samson, R.A. Mycotoxins, drugs and other extrolites produced by species in Penicillium subgenus Penicillium. Stud. Mycol. 2004, 49, 201-241.

5. Bladt, T.T.; Frisvad, J.C.; Knudsen, P.B.; Larsen, T.O. Anticancer and antifungal compounds from Aspergillus, Penicillium and other filamentous fungi. Molecules 2013, 18, 11338-11376.

6. Delgado, J.; Baumann, T.; Ghita, G.; Montserrat, E. Chronic lymphocytic leukemia therapy: Beyound chemoimmunotherapy. Curr. Pharm. Des. 2012, 18, 3356-3362.

7. Tsimberidou, A.-M.; Keating, M.J. Treatment of patients with fludarabine-refractory chronic lymphocytic leukemia: need for new treatment options. Leuk. Lymphoma 2010, 51, 1188-1199.

8. Isfort, S.; Cramer, P.; Hallek, M. Novel and emerging drugs for chronic lymphocytic leukemia. Curr. Cancer Drug Tar. 2012, 12, 471-483. 
9. Burger, J.A.; Tsukada, N.; Burger, M.; Zvaifler, N.J.; Aquila, M.D.; Kipps, T.J. Blood-derived nurse-like cells protect chronic lymphocytic leukemia B cells from spontaneous apoptosis through stromal cell-derived factor-1. Blood 2000, 96, 2655-2663.

10. Munk Pedersen, I.; Reed, J. Microenvironmental interactions and survival of CLL B-cells. Leuk. Lymphoma 2004, 45, 2365-2372.

11. Lagneaux, L.; Delforge, A.; Bron, D.; de Bruyn, C.; Stryckmans, P. Chronic lymphocytic leukemic B cells but not normal B cells are rescued from apoptosis by contact with normal bone marrow stromal cells. Blood 1998, 91, 2387-2396.

12. Seiffert, M.; Stilgenbauer, S.; Döhner, H.; Lichter, P. Efficient nucleofection of primary human B cells and B-CLL cells induces apoptosis, which depends on the microenvironment and on the structure of transfected nucleic acids. Leukemia 2007, 21, 1977-1983.

13. Panayiotidis, P.; Jones, D.; Ganeshaguru, K.; Foroni, L.; Hoffbrand, A.V. Human bone marrow stromal cells prevent apoptosis and support the survival of chronic lymphocytic leukaemia cells in vitro. Br. J. Haematol. 1996, 92, 97-103.

14. Schulz, A.; Toedt, G.; Zenz, T.; Stilgenbauer, S.; Lichter, P.; Seiffert, M. Inflammatory cytokines and signaling pathways are associated with survival of primary chronic lymphocytic leukemia cells in vitro: A dominant role of CCL2. Haematologica 2011, 96, 408-416.

15. Knudsen, P.B.; Hanna, B.; Ohl, S.; Sellner, L.; Zenz, T.; Stilgenbauer, S.; Larsen, T.O.; Lichter, P.; Seiffert, M. Chaetoglobosin A preferentially induces apoptosis in chronic lymphocytic leukemia cells by targeting the cytoskeleton. Leukemia $\mathbf{2 0 1 3}$, in press.

16. Bode, H.B.; Bethe, B.; Höfs, R.; Zeeck, A. Big effects from small changes: Possible ways to explore nature's chemical diversity. ChemBioChem 2002, 3, 619-627.

17. Rebacz, B.; Larsen, T.O.; Clausen, M.H.; Rønnest, M.H.; Löffler, H.; Ho, A.D.; Krämer, A. Identification of griseofulvin as an inhibitor of centrosomal clustering in a phenotype-based screen. Cancer Res. 2007, 67, 6342-6350.

18. Liao, W.-Y.; Shen, C.-N.; Lin, L.-H.; Yang, Y.-L.; Han, H.-Y.; Chen, J.-W.; Kuo, S.-C.; Wu, S.-H.; Liaw, C.-C. Asperjinone, a nor-neolignan, and terrein, a suppressor of ABCG2-expressing breast cancer cells, from thermophilic Aspergillus terreus. J. Nat. Prod. 2012, 75, 630-635.

19. Larsen, T.O.; Smedsgaard, J.; Nielsen, K.F.; Hansen, M.E.; Frisvad, J.C. Phenotypic taxonomy and metabolite profiling in microbial drug discovery. Nat. Prod. Rep. 2005, 22, 672-695.

20. Smedsgaard, J.; Nielsen, J. Metabolite profiling of fungi and yeast: From phenotype to metabolome by MS and informatics. J. Exp. Bot. 2005, 56, 273-286.

21. Månsson, M.; Phipps, R.K.; Gram, L.; Munro, M.H.G.; Larsen, T.O.; Nielsen, K.F. Explorative solid-phase extraction (E-SPE) for accelerated microbial natural product discovery, dereplication, and purification. J. Nat. Prod. 2010, 73, 1126-1132.

22. Smedsgaard, J. Micro-scale extraction procedure for standardized screening of fungal metabolite production in cultures. J. Chromatogr. A 1997, 760, 264-270.

23. Laatsch, H., Ed.; AntiBase 2012; Wiley-VCH: Weinheim, Germany, 2012. Available online: http://eu.wiley.com/WileyCDA/WileyTitle/productCd-3527334068.html (accessed on 5 September 2013).

24. Pohland, A.E.; Schuller, P.L.; Steyn, P.S. Physicochemical data for some selected mycotoxins. Pure Appl. Chem. 1982, 54, 2219-2284. 
25. Raju, M.S.; Wu, G.-S.; Gard, A.; Rosazza, J.P. Microbial transformations of natural antitumor agents. 20. Glucosylation of viridicatumtoxin. J. Nat. Prod. 1982, 45, 321-327.

26. Shao, R.G.; Shimizu, T.; Pommier, Y. Brefeldin A is a potent inducer of apoptosis in human cancer cells independently of p53. Exp. Cell Res. 1996, 227, 190-196.

27. Seya, H.; Nakajima, S.; Kawai, K.-I.; Udagawa, S.-I. Structure and absolute configuration of emestrin, a new macrocyclic epidithiodioxopiperazine from Emericella striata. J. Chem. Soc. Chem. Comm. 1985, 739, 657-658.

28. Seya, H.; Nozawa, K.; Nakajima, S.; Kawai, K.-I.; Udagawa, S.-I. Studies on fungal products. Part 8. Isolation and structure of emestrin, a novel antifungal macrocyclic epidithiodioxopiperazine from Emericeella striata. X-Ray molecular structure of emestrin. J. Chem. Soc. Perk. T. 1 1986, 67, 109-116.

29. Ueno, Y.; Umemori, K.; Nilmi, E.; Tanuma, S.; Nagata, S.; Sugamata, M.; Ihara, T.; Sekljlma, M.; Kawai, K.-I.; Ueno, I.; et al. Induction of apoptosis by T-2 toxin and other natural toxins in HL-60 human promyelotic leukemia cells. Nat. Toxins 1995, 3, 129-137.

30. Terao, K.; Ito, E.; Kawai, K.; Nozawa, K.; Udagawa, S. Experimental acute poisoning in mice induced by emestrin, a new mycotoxin isolated from Emericella species. Mycopathologia 1990, 112, 71-79.

31. Lansden, J.A.; Cole, R.J.; Dorner, J.W.; Cox, R.H.; Cutler, H.G.; Clark, J.D. A new trichothecene mycotoxin isolated from Fusarium tricinctum. J. Agric. Food Chem. 1978, 26, 242-244.

32. Singh, S.B.; Smith, J.L.; Sabnis, G.S.; Dombrowski, A.W.; Schaeffer, J.M.; Goetz, M.A.; Bills, G.F. Structure and conformation of ophiobolin $\mathrm{K}$ and 6- epiophiobolin $\mathrm{K}$ from Aspergillus ustus as a nematocidal agent. Tetrahedron 1991, 47, 6931-6938.

33. Krizsán, K.; Bencsik, O.; Nyilasi, I.; Galgóczy, L.; Vágvölgyi, C.; Papp, T. Effect of the sesterterpene-type metabolites, ophiobolins A and B, on zygomycetes fungi. FEMS Microbiol. Lett. 2010, 313, 135-140.

34. Zhang, D.; Fukuzawa, S.; Satake, M.; Li, X.; Kuranaga, T.; Niitsu, A.; Yoshizawa, K.; Tachibana, K. Ophiobolin $\mathrm{O}$ and 6-epi-ophiobolin $\mathrm{O}$, two new cytotoxic sesterterpenes from the marine derived fungus Aspergillus sp. Nat. Prod. Commun. 2012, 7, 1411-1414.

35. Yang, T.; Lu, Z.; Meng, L.; Wei, S.; Hong, K.; Zhu, W.; Huang, C. The novel agent ophiobolin O induces apoptosis and cell cycle arrest of MCF-7 cells through activation of MAPK signaling pathways. Bioorg. Med. Chem. Lett. 2012, 22, 579-585.

36. Wang, Q.-X.; Yang, J.-L.; Qi, Q.-Y.; Bao, L.; Yang, X.-L.; Liu, M.-M.; Huang, P.; Zhang, L.-X.; Chen, J.-L.; Cai, L.; et al. 3-Anhydro-6-hydroxy-ophiobolin A, a new sesterterpene inhibiting the growth of methicillin-resistant Staphylococcus aureus and inducing the cell death by apoptosis on K562, from the phytopathogenic fungus Bipolaris oryzae. Bioorgan. Med. Chem. Lett. 2013, 23, 3547-3550.

37. Wang, Q.-X.; Bao, L.; Yang, X.-L.; Liu, D.-L.; Guo, H.; Dai, H.-Q.; Song, F.-H.; Zhang, L.-X.; Guo, L.-D.; Li, S.-J.; et al. Ophiobolins P-T, five new cytotoxic and antibacterial sesterterpenes from the endolichenic fungus Ulocladium sp. Fitoterapia 2013, 90, 220-227.

38. Au, T.K.; Chick, W.S.; Leung, P.C. The biology of ophiobolins. Life Sci. 2000, 67, 733-742.

39. Nozoe, S.; Morisaki, M.; Tsuda, K.; Takahashi, N.; Tamura, S.; Ishibashi, K.; Schirasaka, M. The structure of ophiobolin, a C25 terpenoid having a novel skeleton. J. Am. Chem. Soc. 1965, 87, 4968-4970. 
40. Cutler, H.G.; Crumley, F.G.; Cox, R.H.; Springer, J.P.; Arrendale, R.F.; Cole, R.J.; Cole, P.D. Ophiobolins G and H: New fungal metabolites from a novel source, Aspergillus ustus. J. Agric. Food Chem. 1984, 32, 778-782.

41. Chiba, R.; Minami, A.; Gomi, K.; Oikawa, H. Identification of Ophiobolin F synthase by a genome mining approach: A sesterterpene synthase from Aspergillus clavatus. Org. Lett. 2013, 15, 594-597.

42. Shen, X.; Krasnoff, S.B.; Lu, S.W.; Dunbar, C.D.; O’Neal, J.; Turgeon, B.G.; Yoder, O.C.; Gibson, D.M.; Hamann, M.T. Characterization of 6-epi-3-anhydroophiobolin B from Cochliobolus heterostrophus. J. Nat. Prod. 1999, 62, 895-897.

43. Wei, H.; Itoh, T.; Kinoshita, M.; Nakai, Y.; Kurotaki, M.; Kobayashi, M. Cytotoxic sesterterpenes, 6-epi-ophiobolin $\mathrm{G}$ and 6-epi-ophiobolin $\mathrm{N}$, from marine derived fungus Emericella variecolor GF10. Tetrahedron 2004, 60, 6015-6019.

44. Fujiwara, H.; Matsunaga, K.; Kumagai, H.; Ishizuka, M.; Ohizumi, Y. Ophiobolin A, a novel apoptosis-inducing agent from fungus strain f-7438. Pharm. Pharmacol. Commun. 2000, 6, 427-431.

45. Bury, M.; Novo-Uzal, E.; Andolfi, A.; Cimini, S.; Wauthoz, N.; Heffeter, P.; Lallemand, B.; Avolio, F.; Delporte, C.; Cimmino, A.; et al. Ophiobolin A, a sesterterpenoid fungal phytotoxin, displays higher in vitro growth-inhibitory effects in mammalian than in plant cells and displays in vivo antitumor activity. Int. J. Oncol. 2013, 43, 575-585.

46. Samson, R.A.; Varga, J.; Meijer, M.; Frisvad, J.C. New taxa in Aspergillus section Usti. Stud. Mycol. 2011, 69, 81-97.

47. Nozoe, S.; Hirai, K.; Tusda, K. The structure of zizanin-A and -B, C25-terpenoids isolated from Helminthosporium zizaniae. Tetrahedron Lett. 1966, 20, 2211-2216.

48. Li, E.; Clark, A.M.; Rotella, D.P.; Hufford, C.D. Microbial metabolites of ophiobolin A and antimicrobial evaluation of ophiobolins. J. Nat. Prod. 1995, 58, 74-81.

49. Tsipouras, A.; Adefarati, A.A.; Tkacz, J.S.; Frazier, E.G.; Rohrer, S.P.; Birzin, E.; Rosegay, A.; Zink, D.L.; Goetz, M.A.; Singh, S.B.; et al. Ophiobolin M and analogues, noncompetitive inhibitors of ivermectin binding with nematocidal activity. Bioorg. Med. Chem. 1996, 4, 531-536.

50. Canonica, L.; Fiecchi, A.; Galli Kienle, M.; Ranzi, B.M.; Scala, A. The biosynthesis of ophiobolins. Tetrahedron Lett. 1967, 35, 3371-3376.

51. De Vries-van Leeuwen, I.J.; Kortekaas-Thijssen, C.; Mandouckou, J.A.N.; Kas, S.; Evidente, A.; de Boer, A.H. Fusicoccin-A selectively induces apoptosis in tumor cells after interferon-alpha priming. Cancer Lett. 2010, 293, 198-206.

52. Evidente, A.; Andolfi, A.; Cimmino, A.; Vurro, M.; Fracchiolla, M.; Charudattan, R. Herbicidal potential of ophiobolins produced by Drechslera gigantea. J. Agric. Food Chem. 2006, 54, 1779-1783.

53. Seiffert, M.; Schulz, A.; Ohl, S.; Döhner, H.; Stilgenbauer, S.; Lichter, P. Soluble CD14 is a novel monocyte-derived survival factor for chronic lymphocytic leukemia cells, which is induced by CLL cells in vitro and present at abnormally high levels in vivo. Blood 2010, 116, 4223-4230.

Sample Availability: Not available.

(C) 2013 by the authors; licensee MDPI, Basel, Switzerland. This article is an open access article distributed under the terms and conditions of the Creative Commons Attribution license (http://creativecommons.org/licenses/by/3.0/). 